\title{
Proceedings of the Association of British Neurologists and the Society of British Neurological Surgeons, University of Liverpool, 5-7 April 1995
}

\section{Platform Presentations}

LOWER CRANIAL NERVE COMPRESSION SYNDROMES

JB Miles, PR Eldridge, L Dunn, I Mackenzie, J Meaney. Walton Centre for Neurology and Neurosurgery, Liverpool, UK

Objectives-To validate the causal significance of compression and the effectiveness and safety of microvascular decompression (MVD) in syndromes of the V, VII, VIII, IX and Xth cranial nerves. ${ }^{1}$

Design-Clinical, neurological, and imaging assessment, including magnetic resonance tomo-angiography (MRTA), ${ }^{2}$ followed by MVD during continuous brainstem (auditory) monitoring.

Patients-110 patients with trigeminal neuralgia (TGN); 25 patients with hemifacial spasm (HFS); two patients with tinnitus; six patients with IX or X neuralgia; six patients with systemic hypertension (HBP).

Outcome-The quantitative effectiveness of MVD including morbidity data, has been established by questionnaire and interview over the 15 year study.

Results-6\% of TGN recurred; $20 \%$ HFS was unrelieved or recurred; the two patients with tinnitus were satisfactorily relieved; five of the six patients with IX/X neuralgia were cured, and three of the six patients with HBP seemed improved.

Conclusions-Microvascular decompression is more effective than other existing methods in relieving symptoms and signs of lower cranial nerve compression syndromes with acceptable safety using diagnostic imaging and interoperative monitoring. Outcome measurement supports the compression as being significantly involved in achieving relief rather than this being simply due to nerve injury.

[SBNS]

1 Janetta PJ. Neurovascular compression in cranial nerve and systemic diseases. Ann Surg 1980;192:518-25.

2 Meaney JFM, Miles JB, Nixon TE, et al. Vascular contact with the fifth cranial nerve at the pons in patients with trigeminal neural gia: detection with $3 \mathrm{D}$ FISP imaging. $A \mathcal{F} R$ Am f Roentgenology 1994;163:1447-62.

RISK OF ACCIDENTS IN DRIVERS WITH EPILEPSY

D Chadwick. University of Liverpool, Liverpool, UK

Between June 1992 and May 1993 a survey was undertaken of driving and accident experience in people with a history of epilepsy communicating with the DVLA. 24000 questionnaires were issued as part of the routine relicensing of drivers at three year intervals, of which just over 17000 were returned (response rate of $71 \%$ ). In addition, 468 questionnaires were issued to drivers reporting recent seizures at the DVLA of which 291 were returned (response rate of $62 \%$ ). The questionnaire used identical methods to a cohort of non- epileptic drivers carried out between 1990 and 1991 by the Transport and Road Research Laboratory (8888 drivers). Both surveys were retrospective and collected data for three years before the survey.

The relative risk for involvement in any accident during this period was $0.95(95 \%$ CI 0.88-1.02). However, the adjusted relative risk for involvement in an injury producing accident was somewhat raised in the epilepsy group $1 \cdot 1 \quad(0 \cdot 91-1 \cdot 3)$. The adjusted odds ratio for serious physical injury was $1.37(1.02-1 \cdot 84)$. In the epilepsy group there were 12 drivers involved in an accident resulting in a fatality, but none in the TRL group.

The factors that influenced the risk of accident rates were not dissimilar in the two groups, age, driving experience, and mileage being the most important. The absence of any seizure within the three year period of the survey halved the risk of involvement in an accident producing some form of serious physical injury or fatality. No other clinical factors in the epilepsy group seemed to influence accident risks. [ABN]

NEURAL TRANSPLANTATION BY ER HITCHCOCK: TREATING PARKINSON'S DISEASE BY GRAFTS OF FOETAL MESENCEPHALON AND STRIATUM CHA Meyer. Midlands Centre for Neurology and Neurosurgery, Birmingham, UK

Objectives-Experimental neurosurgical treatment of Parkinson's disease.

Design-Since 1988, 55 patients with severe Parkinson's disease (Hoehn and Yahr stage IV, V) have been treated at the Midlands Centre for Neurology and Neurosurgery by stereotactic implantation of brain tissue from spontaneously aborted human foetuses. Each implantation used a single foetus of second trimester (11-20 weeks post-gestational); grafts dissected 5-12 hours after foetal expulsion, disaggregated mechanically, and implanted as clumps (not as cell suspensions); there was no immunosuppressive therapy.

Consecutive patients formed five series differing in site of implantation (caudate or putamen, unilateral or bilateral) and in nature of graft (foetal mesencephalon alone or with striatum).

In the final series (described here) grafts of foetal mesencephalon and striatum were implanted bilaterally into the head of the caudate nucleus.

Patients-Seven patients (Hoehn and Yahr stage IV, V) aged $46-62$ years.

Results-All seven patients improved. There were very good group improvements, statistically significant (Wilcoxon), in a wide range of activities of daily living measures, clinical neurology, and timed motor tasks sustained throughout 18 months follow up-with substantial reduction in need for dopaminergic medication.
Conclusions-Results were strikingly better than those of all four previous series, which used foetal mesencephalon alone. This experimental technique shows promise for treating Parkinson's disease. [SBNS]

EN BLOC TEMPORAL LOBECTOMY $V$ SELECTIVE AMYGDALOHIPPOCAMPECTOMY AS TREATMENTS FOR INTRACTABLE EPILEPSY DUE TO HIPPOCAMPAL SCLEROSIS JM Oxbury, CBT Adams, SM Oxbury, KN Carpenter, SA Renowden. Radcliffe Infirmary, Oxford, UK

Various surgical treatments for intractable epilepsy due to hippocampal sclerosis are recommended. It is uncertain which is most effective. Sixty nine patients with this condition were treated-50 by Falconer type en bloc temporal lobectomy (TL), 19 by selective amygdalohippocampectomy (AH). The two methods are compared. Of particular concern was seizure outcome and verbal memory loss after left operations. Eleven $\mathrm{AH}$ were transcortical via the middle temporal gyrus, and eight were trans-sylvian.

Two years after operation $54 \%$ had not had any seizure since surgery; $23 \%$ had experienced only very occasional seizures (77\% in Engel grades I+ II). Thirty of 41 cases $(73 \%)$ were seizure free five years after operation. Neither seizure outcome nor serious unwanted effects differed significantly according to type of surgery.

Neuropsychological assessment two years after operation showed less verbal memory decline after left AH than after left TL. Left $\mathrm{AH}$, but not left TL, gave significant improvements in verbal IQ and non-verbal memory. Performance IQ improved in both groups. Postoperative MRI showed less temporal lobe white matter disruption after trans-sylvian $\mathrm{AH}$ than after the transcortical approach.

It is concluded that trans-sylvian $\mathrm{AH}$ is preferable to TL as a treatment for most cases of intractable epilepsy due to left hippocampal sclerosis and probably also that due to right hippocampal sclerosis. [ABN]

VOLUMETRIC MAGNETIC RESONANCE IMAGING (MRI) IN CHRONIC EPILEPSY SM Sisodiya, SL Free, DR Fish, SD Shorvon. Institute of Neurology, London, UK

Volumetric MRI enables detailed examination of cortical anatomy. An investigation into chronic epilepsy using MRI and postprocessing techniques is being carried out.

Scanning patients with primary generalised epilepsy showed underlying structural abnormalities in six cases. Three had subependymal heterotopia and three hippocampal asymmetry: one of these improved after temporal lobectomy. Reconstruction of 
a three dimensional image of the cerebral hemispheres and comparison of the gyral patterns demonstrated with control subjects showed gyral abnormalities in 16 of 30 patients with normal MRI on inspection of routine two dimensional images, and additional gyral abnormalities in three of 18 patients with cortical dysgenesis observed on routine images. Analysis of the distribution of cerebral grey/white matter, by division of reconstructed objects into coronal 10ths, allows measurement of cerebral structure. The existence of structural abnormality beyond the visualised lesion was shown in 15 of 18 patients with cortical dysgenesis on routine imaging and in nine of 14 patients with lesions demonstrated only on reconstructed images. This supports the hypothesis that cortical dysgenesis is an extensive disorder. Block analysis has also shown structural disruption in patients with mental retardation and epilepsy with normal imaging and reconstruction.

Volumetric MRI is important in the investigation of epilepsy. Visual inspection of data alone is not adequate in cases where no lesion is found.

[ABN]

IMPROVEMENT OF EPILEPSY AFTER STEREOTACTIC RADIOSURGERY FOR ARTERIOVENOUS MALFORMATIONS AA Kemeny, M Foroughi, L Walton, DMC Forster. National Centre for Stereotactic Radiosurgery, Sheffield, UK

Objectives-Stereotactic radiosurgery (STRS) is primarily aimed at achieving thromboobliteration of arteriovenous malformations (AVMs). This study was carried out to evaluate the degree of amelioration in seizure activity observed clinically as an additional benefit after STRS.

Design-Telephone interview with patients and analysis of the prospectively maintained departmental database.

Patients-From over 1500 patients $269 \mathrm{had}$ epilepsy; 149 were included in the analysis who fulfilled the following criteria: active epilepsy before STRS; follow up longer than two years; angiographic control.

Outcome measures-The patients classified the severity and frequency of their seizures subjectively into improved/no change/worse. A category of "no fits" was assigned to those with no seizures for a year.

Results-Fifty four per cent of patients became fit free and $29 \%$ had subjective improvement. The size of the AVM nidus and the radicality of the treatment plan affected the change in epilepsy. More than $50 \%$ of those whose AVMs were not obliterated reported worthwhile improvement in their epilepsy.

Conclusion-Improvement after STRS in epilepsy is a realistic expectation in most patients with AVM.

[SBNS]

"C-FLUMAZENIL PET AND VOLUMETRIC MRI IN MESTAL TEMPORAL LOBE EPILEPSY

MJ Koepp, MP Richardson, DJ Brooks, DR Fish, JS Duncan. Institute of Neurology, London, UK

${ }^{11}$ C-Flumazenil PET has been used to compare extent of loss of benzodiazepine receptor density with volumetric $M R I$ in patients with epilepsy due to mesial temporal sclerosis (MTS). ${ }^{11} \mathrm{C}-$ Flumazenil binding has been shown to be reduced in MTS. To date, no studies have formally compared extent of sclerosis with volumetric MRI and 3D ${ }^{11} \mathrm{C}$-flumazenil PETchanges. It is hypothesised that the reduction of hippocampal BZ/GABA-A receptor density in patients with MTS is over and above the loss of hippocampal volume.

Ten patients with MTS and pronounced unilateral hippocampal sclerosis were studied. ${ }^{11} \mathrm{C}$-Flumazenil PET Vd images were produced. These scans were coregistered with high resolution MRI. The hippocampus and neighbouring gyri were delineated on coronal MRI sections. Asymmetry indices were compared with 10 age matched normal controls. In all patients reduction of ${ }^{11} \mathrm{C}$-flumazenil $\mathrm{Vd}$ was correlated with the side of hippocampal sclerosis. On average ${ }^{11} \mathrm{C}$-flumazenil Vd was reduced in the smaller hippocampus by $20 \%$. Changes of BZ/GABA-A receptor density in the other hippocampus lay within normal limits.

In conclusion, there is a reduction of BZ/GABA-A receptor density in the hippocampus of patients with mesial temporal lobe epilepsy over and above loss of hippocampal volume. This may be of importance in planning the extent of resection in patients with MTLE.

[ABN]

\section{SEIZURE FUNCTIONAL OUTCOME ONE YEAR} AFTER HEMISPHERECTOMY GF Tuite, JH Cross, BG Neville, WF Harkness. Great Ormond Street Hospital for Sick Children, London, UK

One year outcome data after hemispherectomy in 20 paediatric patients with severe medically intractable seizures is presented. Their average age at the time of surgery was 4.7 years (range 0.5 to 16 ) with an equal number of boys and girls. All patients had a preoperative hemiparesis but they varied widely in their neurological disability. Two patients presented with epilepsia partialis continua. Preoperative electroencephalography and MRI localised the abnormality to a single hemisphere in all cases (9L, 11R).

A functional hemispherectomy was the preferred operation, but anatomical hemispherectomy was performed in three cases. Most had hemimegancephaly (five) or cortical dysplasia (six); the rest had a porencephalic cyst (four), Rasmussen's encephalitis (two), Sturge-Weber syndrome (two), and a large extradural cyst (one). All patients tolerated their operation well, with no complications in the immediate perioperative period

All of the patients have had at least a $75 \%$ reduction in seizure frequency and 16 are seizure free (follow up one to 3.5 years). Three patients $(15 \%)$ have required the placement of a ventriculoperitoneal shunt. There was worsening of motor function in two patients. The striking feature in most cases was the developmental improvement that occurred after surgery.

[SBNS]
SUBARACHNOID HAEMORRHAGE AND THE INFLAMMATORY CYTOKINE RESPONSE RH Lye, WR Lamb, PEC Brenchley. University of Manchester, Manchester, UK

Introduction-There is evidence that the immune system is activated after aneurysmal subarachnoid haemorrhage (SAH). The proinflammatory cytokines IL-1 $\beta$, IL-6, and TNF $\alpha$ were measured in 10 patients who had had SAH.

Method-The in vivo cytokine response was monitored in eight patients by daily measurements of systemic concentrations in serum during their hospital stay. A whole blood endotoxin stimulation assay was also used for in vitro assay of cytokine in the same blood samples. This gave a measure of each patient's total capacity to produce cytokines in response to a stimulus.

Results-All patients underwent craniotomy with clipping of the aneurysm. No systemic cytokine release was seen among this group, but the in vitro cytokine pattern during the postoperative period showed an upward trend in two patients, a downward trend in three, and violent oscillation of cytokine over several days in the remaining three patients. Interestingly, all patients showed a significant decrease in their ability to secrete TNFa after operation $(P<0.05)$ with a highly significant corresponding increase in the two types of soluble TNF receptors TNFp55 and TNFp75 ( $P<0.001)$. Similar findings were not seen for either IL-1 $a$ or IL-6.

Conclusions-These preliminary findings highlight an alteration of the physiological production of TNF $a$ and its receptors p55 and p75 after SAH.

[SBNS]

THE EFFECT OF CSF PROTEIN

CONCENTRATION ON SUBSEQUENT SHUNT COMPLICATIONS: A PROSPECTIVE STUDY

HL Brydon, RD Hayward, WFJ Harkness, R Bayston, EJ Thompson, G Keir. Hospital for Sick Children, Institute of Child Health, and Institute of Neurology, London, UK

Objective-To assess the effect of the CSF protein concentration on subsequent shunt complications.

Design-A prospective clinical study comparing complications arising within two months of surgery to the peroperative CSF protein concentration.

Subjects-Ninety five patients undergoing shunt surgery (new insertion or revision) during a 15 month period. In total, 132 definitive shunt operations were performed. Outcome measures-Shunt infection, obstruction and overdrainage occurring within eight weeks of surgery. Statistical analysis was performed with the Mann-Whitney $U$ test and the $\chi^{2}$ test.

Results-There were 12 instances of shunt obstruction, 10 shunt infections and three patients with significant overdrainage. The total protein content of the infection $(0.1>$ $P>0.05)$ and obstruction groups $(0.5>P>$ $0 \cdot 1)$ was not significantly different from those without complications. The overdrainage group had significantly less CSF protein $(0.5>P>0.02)$, but this group only consisted of three CSF specimens, all of which had a normal protein content. Conclusions-A raised CSF protein content does not increase the risk of shunt 
complications; there is no reason why shunting should be delayed in patients with a high CSF protein content. [SBNS]

NUMB-CLUMSY HAND IN HIGH CERVICAL CORD LESIONS

V Kunanandam, K Ajay Kumar. Hull Royal Infirmary, Hull, UK

Objective-To determine the pathogenic mechanism for numb-clumsy hand.

Design-Correlation of clinical features, radiological findings (MRI), and pathology in patients with numb-clumsy hand.

Subjects-30 patients with numb-clumsy hands were identified in a series of 53 patients operated for high cervical cord lesions (above C3/4) during the period 1993 to 1994 (September).

Assessment-Evidence of posterior column involvement, cord signals in MRI and/or severe compression in CT myelogram, and nature of pathological lesions.

Results-Numb-clumsy hand was associated with no objective posterior column involvement (clinical or EMG/NC study), with severe cord compression on CT myelogram/MRI and cord signal on MRI and with pathological lesions: C3/4 spondylosis (19), $\mathrm{C} 1 / 2$ rheumatoid subluxation (five), tumours (two), and others (four).

Conclusion - Numb-clumsy hand was associated with high cervical (C1-C4) lesions causing severe anterior central compression of cord and intrinsic cord signal on MRI, but minimal objective neurological signs. Pathogenic mechanisms are probably related to compression and disconnection of spinocerebellar tracts. ${ }^{12}$

1 Chang $\mathrm{MH}$, Liao KK, Cheung SC, et al. "Numb clumsy hands" and tactile agnosia secondary to high cervical spondylotic myelopathy: a clinical and physiological correlation. Acta Neurol Scand 1992; 86:622-5.

2 Voskuhl RR, Hinton RC. Sensory impairment in the hands secondary to spondylotic compression of the cervical spinal cord. Arch pression of the cervical
Neurol 1990;47:309-11. [SBNS]

FAMILIAL NON-SPECIFIC DEMENTIA MAPS TO CHROMOSOME 3

JM Brown, T Ashworth, S Gydesen, M Rossor, J Collinge. St Mary's Hospital Medical School, London, UK

A substantial minority of patients with presenile dementias lack distinctive inclusion bodies, plaques or tangles on pathological examination. Such dementias typically present with evidence of frontal lobe dysfunction and are probably the commonest cause of frontal lobe dementia. These dementias have been termed non-specific dementias (NSD). Half the reported cases of NSD have a positive family history of dementia. Clinical and molecular genetic studies on the largest published family with NSD have been conducted. There are 20 affected patients in three generations, the disease is inherited in an autosomal dominant fashion. After running over 170 microsatellite probes and excluding $75 \%$ of the genome the disease locus has now been assigned to the pericentromeric region of chromosome 3 . Haplotype analysis shows a common region shared between all affected patients. The maximum pairwise lod score obtained was $+4 \cdot 2$, multipoint analyses increased this to $+5 \cdot 8$. The clinical studies show that paternally inherited cases develop the disease at a significantly lower age than their affected parent. This anticipation of the disease onset with paternal transmission suggests that the disease is produced by a trinucleotide repeat expansion mutation. Some other neurogenetic diseases, including Huntington's disease, have now been related to such mutations.

[ABN]

NEUROPSYCHOLOGY AND SPECT IN

DIAGNOSIS AND STAGING OF ALZHEIMER'S DISEASE

JDW Greene, JR Hodges. University of Cambridge, Cambridge, UK

Given the advent of drug treatments for dementia of the Alzheimer type (DAT), it is important to develop more accurate methods for diagnosis and staging. The role of neuropsychology and SPECT imaging in diagnosis and staging DAT in 33 patients with mild disease and 30 matched controls were studied. Working, episodic, remote, and semantic memory were assessed. TcHMPAO SPECT was analysed quantitatively to obtain measures of regional cerebral blood flow.

For diagnosis, the memory tests were highly discriminatory, with a canonical correlation coefficient of 0.975 . The most useful test was delayed verbal recall; SPECT data were, by contrast, of less use in predicting group membership; $33 \%$ of patients had normal SPECT scans.

For staging, stepwise regression analysis using all memory tests could predict $79 \%$ of the variance in mini mental state examination scores. The measures most useful for staging were immediate, recognition, semantic, and autobiographical memory. SPECT data were again of less use in modelling severity of disease; only $38 \%$ of the variance in MMSE scores could be predicted from SPECT data.

Neuropsychology has been shown to be superior to SPECT both in diagnosis and staging DAT. Different memory tests are useful for diagnosis and staging: delayed verbal recall is the best discriminator, whereas immediate, recognition, autobiographical, and semantic memory, are of most use in staging severity. [ABN]

MITOCHONDRIAL ENCEPHALOMYOPATHY WITH MULTIPLE MITOCHONDRIAL DNA DELETIONS: A REPORT OF TWO FAMILIES AND TWO SPORADIC CASES WITH UNUSUAL CLINICAL AND NEUROPATHOLOGICAL FEATURES

RM Chalmers, M Brockington, RS Howard, BRF Lecky, AE Harding. National Hospital for Neurology and Neurosurgery, London, UK

Most diseases associated with abnormalities of human mitochondrial DNA (mtDNA) occur either sporadically or show maternal inheritance. Recently, a mitochondria myopathy associated with multiple deletions of $\mathrm{mtDNA}$ has been identified in pedigrees that show an autosomal dominant mode of inheritance. In this syndrome the mtDNA defect is presumed secondary to a nuclear gene mutation.

The first two British kindreds with this disorder and two sporadic cases are reported. All patients had adult onset progressive external ophthalmoplegia and muscle weakness, with muscle biopsy appearances of a mitochondrial myopathy. Southern blot analysis of total muscle DNA digested with appropriate restriction enzymes shows a pattern consistent with multiple populations of mtDNA.

The cases exhibit, in addition, some unusual clinical features. These include pigmentary retinopathy and tremor; the last was levodopa responsive and associated with rigidity and micrographia in one family. One family and both sporadic cases have a neuropathy and nerve biopsy confirms the indication of an axonal neuropathy suggested from nerve conduction studies. Postmortem examination of one patient showed pronounced nigral degeneration, which is of interest in relation to the parkinsonism seen and the evidence of mitochondrial chain dysfunction in Parkinson's disease. [ABN]

OCULOMOTOR FUNCTION IN MOTOR NEURON DISEASE

S Shaunak, E O'Sullivan, R Orrell, R Lane, $C$ Kennard. Charing Cross and Westminster Medical School, London, UK

Although it is generally held that the oculomotor system is spared in motor neuron disease (MND), several recent oculographic studies of reflexive saccades and smooth pursuit in MND have yielded conflicting results. Oculomotor function was therefore studied in a range of paradigms, some of which are considered to involve the frontal lobes in their execution.

Eye movements in 17 patients with MND and 11 age matched normal controls were recorded with the scleral search coil technique. Smooth pursuit, fixation, and reflexive, remembered, and antisaccade paradigms were studied. Results were analysed for saccadic latency, peak velocity, gain, final eye position (FEP), antisaccade/ remembered saccade error rates, pursuit peak velocity gain, and square wave jerk frequency. Reflexive saccades were unimpaired in patients with MND compared with controls. Error rates for both antisaccades and remembered saccades were elevated in the MND group (antisaccades: MND 31.9 (24.9)\%, control $10.3(9.6) \%, P=0.004$; remembered saccades: MND $30.8(24.6) \%$, control $12.4(14.4) \%, P=0.02)$. Antisaccade and remembered saccade latencies were also prolonged (antisaccades: MND $376.9(87.9) \mathrm{ms}$, control $303.5(53.9) \mathrm{ms}$ $P=0.01$; remembered saccades: $M N D$ 318.1 (74.9) $\mathrm{ms}$, control $258.3(43.76) \mathrm{ms}, \mathrm{P}=$ $0.02)$. Square wave jerk frequency was increased in patients with MND (MND 32.9 $(19.6) \mathrm{min}$, control $8.7 \quad(4.7) \mathrm{min}, \mathrm{P}=$ 0.0007 ), but smooth pursuit showed no impairment.

These findings of prolonged volitional saccade latency and high distractability suggest prefrontal impairment in $M N D$, and are consistent with the results of recent neuropsychological, pathological, and PET studies. [ABN] 
A STUDY OF THE CAUSES OF LATE FUNCTIONAL DETERIORATION AFTER PREVIOUS POLIOMYELITIS

D Kidd, RS Howard, E Chroni, FW Heatley, A Williams, GT Spencer. St Thomas' Hospital, London, UK

Many patients with previous poliomyelitis develop "postpolio syndromes" (PPS) in which late functional deterioration follows a period of relative stability. The frequency with which PPS can be attributed to clearly defined causes remains uncertain. A review of newly referred patients with previous poliomyelitis seen consecutively over a three year period was undertaken. There were 156 patients ( 51 men, 105 women, mean age 52 (range 17-80) years) who had developed acute paralytic poliomyelitis at a mean age of $6(0.5-42)$ years. Eighteen patients had been ventilated, and 124 had had severe weakness during the acute illness. After recovery, 22 were wheelchair bound and 31 mobile with severe disability. 140 patients $(90 \%)$ developed symptoms of functional deterioration at a mean time interval of $42(17-76)$ years after the paralytic illness. Functional deterioration was associated with orthopaedic disorders in 125 cases, neurological disorders in 16 , respiratory disorders in 12 , and others in 13. Treatment of bone and joint abnormalities including surgery (26 cases) and provision of orthotic appliances (70 cases) with physiotherapy, was associated with functional improvement in $90 \%$ of those followed up. Other treatments included weight loss, ventilatory support, and pain relief. In this series progressive postpolio muscular atrophy was not noted. Functional deterioration was common and associated with orthopaedic, neurological, respiratory, and general medical factors which are potentially treatable.

[ABN]

EFFECT OF SURGICAL REPAIR ON PAIN RELIEF AFTER BRACHIAL PLEXUS INJURY IN ADULTS JS Berman, $M$ Taggart, $P$ Anand, $R$ Birch. Royal London Hospital Medical College and Royal National Orthopaedic Hospital, London, UK

The characteristic pain after root avulsion begins within weeks of brachial plexus injury in adults, and persists for many years, still being severe in $25 \%$ of patients after four years. Surgical treatment of avulsion injuries led to preliminary observations that the surgery accelerated resolution of pain. This study examined the effect of surgerynerve grafting and transfer-on the duration and severity of root avulsion pain. 487 patients were studied prospectively over 10 years with preganglionic root avulsions alone or in combination with postganglionic ruptures or lesions in continuity (LIC). They were compared with pure ruptures and pure LIC. In the avulsion group, pain was reduced substantially at an average time of 175 days after operation, in comparison with 68 days for the pure rupture group and 58 days for the pure LIC group. Of the 39 pure avulsion patients, only three reported no improvement in their pain 20 months after surgery, the median time for improvement being 120 days. These findings support the view that nerve repair accelerates pain amelioration after brachial plexus injury. Pain resolution usually preceded recovery of motor or sensory function.

[ABN]

\section{A COMPREHENSIVE}

CLINICONEUROPHYSIOLOGICAL STUDY OF IDIOPATHIC GENERALISED EPILEPSIES WITH ABSENCES IN ADULTS

CP Panayiotopoulos, S Giannakodimos. St Thomas' Hospital, London, UK

Eighty five patients over 16 years of age with typical absences (TAs) were studied. All had EEG confirmation, and $47 \%$ had additional video-EEG documentation of TAs. Prevalence of TAs was $22 \%$ among 410 adults with epilepsies and $63 \%$ among idiopathic generalised epilepsies (IGE).

The clinico-EEG manifestations of absences were syndrome related. 30 patients had juvenile myoclonic epilepsy; all had mild absences and myoclonic jerks on awakening, and all but two had generalised tonic-clonic seizures (GTCS). 10 patients had juvenile absence epilepsy; all had severe absences and all but one GTCS. 11 patients had eyelid myoclonia with absences, a syndrome characterised by eyelid myoclonia with absences and photosensitivity. Seven patients had perioral myoclonia with absences, a syndrome characterised by TAs associated with ictal rhythmic perioral myoclonia. Four patients had predominantly photo or pattern induced TAs. Twelve of the remaining patients, showed remarkably similar clinicoEEG features, which were not fortuitous. A new syndrome characterised by "phantom absences" and GTCS, is proposed. The name "phantom absences" has been coined to denote TAs that are so mild that they are inconspicuous to the patient and invisible to the observer. Absences in adults constitute a diagnostic challenge to physicians and have important implications in the syndromic classification and management of patients. [ABN]

DIAGNOSIS AND MANAGEMENT OF EPILEPSY AND "FUNNY TURNS" IN A SPECIALIST CLINIC D Smith, B Dafalla, DW Chadwick. Walton Centre for Neurology and Neurosurgery, Liverpool, UK

Patients with "funny turns" are often referred to neurologists with a previous or possible diagnosis of epilepsy. This study was designed to assess the frequency of factors contributing to and the consequences of an erroneous diagnosis of epilepsy, the outcome of patients referred with "refractory seizures", and the relative roles of clinical acumen and investigations in establishing the cause of "funny turns".

A retrospective analysis of the case records of 324 patients was conducted. The sample was divided into those exposed to antiepileptic drugs (AEDs) $(n=184)$, of whom 92 were said to have refractory seizures, and those who had not received treatment $(n=$ 140).

The overall misdiagnosis rate was $26 \cdot 1 \%$ (46/184) with inadequate history taking and misinterpretation of EEG equally responsible. 19/40 reported side effects from AEDs while unnecessary driving restrictions and employment difficulties were encountered by $12 / 33$ and $5 / 33$ respectively. Of those labelled "refractory epilepsy", 12 did not have epilepsy and 41 were rendered seizure free or significantly improved by optimal use of AEDs or surgery. Diagnosis of "funny turns" was usually achieved on clinical grounds alone except in patients with pseudoseizures on AEDs $58 \%$ of whom required investigation to refute the diagnosis of epilepsy.

These data show suboptimal diagnostic and management services for patients with "funny turns" and epilepsy respectively and provides a strong case for expansion of specialist services and open access to multidisciplinary epilepsy clinics.

[ABN]

REGIONAL CEREBRAL BLOOD FLOW DURING POSTERIOR SEIZURES: AN HMPAO SPECT STUDY

R Duncan, J Patterson, R Roberts, D Hadley. Universities of Glasgow and Dundee, UK

Ictal HMPAO SPECT was used to study five patients whose clinical and surface video EEG data indicated seizure origin in the area of the temporoparieto-occipital junction (TPOJ). Three patients had structural lesions in the area of the TPOJ. HMPAO injection was carried out from 30-120 seconds from clinical seizure onset. Acquisition was carried out with a Strichmann 810 dedicated head imager.

Interictal SPECT showed perfusion deficits in keeping with anatomical lesions in three patients, hemispheric hypoperfusion on the side of electrical seizure origin in a fourth, and was normal in a fifth. Ictal images showed hyperperfusion in the area of the TPOJ in all five patients. This hyperperfusion extended anteriorly into the ipsilateral lateral temporal cortex and pole, with hyperperfusion of a lesser degree in the ipsilateral mesial temporal cortex, and ipsilateral hyperperfusion of the basal ganglia in two patients. In two patients there was ictal hypoperfusion of the rest of the ipsilateral hemisphere. Measured as a change in asymmetry index with respect to the interictal image, ictal hyperperfusion was most pronounced at the TPOJ in all five cases.

It is concluded that ictal SPECT shows distinct patterns of perfusion in TPOJ seizures, and can distinguish them from mesial temporal seizures.

[ABN]

EYELID MYOCLONIA WITH ABSENCES: A CLINICAL AND VIDEO-EEG STUDY IN ADULTS S Giannakodimos, CP Panayiotopoulos. St Thomas' Hospital, London, UK

Eyelid myoclonia with absences (EMA) is an idiopathic generalised epilepsy (IGE) syndrome, manifested by eyelid myoclonia associated with brief absences and photosensitivity. The ictal EEG shows generalised 3-6 $\mathrm{Hz}$ spike/polyspike-slow wave activity, mainly on eye closure.

This is the first clinical and video-EEG study of adults with EMA. Their prevalence in the adult epilepsy clinic was $2 \cdot 7 \%$ among 410 epileptic patients, $8 \cdot 1 \%$ among patients with IGE, and $12.9 \%$ among patients with 
IGE with absences. There were 11 patients with EMA, all female, with a mean age of 30.9 years. Reported onset of absences was at a mean age of 7.8 years. Eyelid myoclonia with absences was confirmed with videoEEG in 10 patients. The seizures consisted of eyelid myoclonia alone or preceding brief (3-6s) absences. Ictal clinical and EEG manifestations occurred mainly after eye closure and were inhibited by total darkness. Only five patients showed photoparoxysmal responses as adults, although all had a previous clinical and/or EEG documentation of photosensitivity. None of the patients had self induced seizures. Infrequent generalised tonic clonic seizures occurred in 10 patients, and were precipitated mainly by lights, sleep deprivation, fatigue, and menstruation. Mild myoclonic jerks of the upper limbs occurred in six patients.

Eyelid monoclonia with absences is often resistant to medication and persists into adult life.

[ABN]

MEDULLOBLASTOMA: HAS THERE BEEN ANY IMPROVEMENT IN FIVE YEAR SURVIVAL OVER THE PAST 20 YEARS?

KM David, ATH Casey, RD Hayward, WFJ Harkness. Great Ormond Street Hospital for Sick Children, London, UK

The large number of cases of medulloblastoma seen at Great Ormond Street allows a unique opportunity to view longitudinally the effect that modern methods of investigation and treatment have on the prognosis. A cohort of cases treated over a 10 year period for whom a five year follow up was available (1980-9) have been analysed. Eighty children were admitted during this time, of whom 75 went on to receive radiotherapy and/or chemotherapy (operative mortality $5 \%)$. Forty patients were alive and 38 disease free at five years after diagnosis- $-90 \%$ of those with favourable prognostic features (no perioperative spinal metastases, radical surgery) and $10 \%$ of those without. Comparison with an earlier cohort of cases from this institution (1965-74) gives the following information.

Modern methods of investigation and treatment have clearly improved the outlook for patients with medulloblastoma-but the greatest advance remains the changes to radiotherapy regimes introduced in the $1960 \mathrm{~s}$. It is suggested that there is unlikely to be any further dramatic improvement until radical changes can be made in either the chemotherapy regimes (for example, high dose chemotherapy with bone marrow rescue) or in immunological or gene mediated therapies.

1 McIntosh N. Medulloblastoma-a changing [SBNS]

prognosis? Arch Dis Child 1979;54:200-3.

MORBIDITY OF SURGERY FOR

INTRAVENTRICULAR CRANIOPHARYNGIOMAS MJ Davies, TT King. Royal London Hospital, London, UK

Craniopharyngiomas situated wholly within the third ventricle are rare and only 31 cases (including the cases to be presented here) are reported in the literature. ${ }^{1}$ Five cases treated surgically by one of the authors (TTK) are reviewed. Three of these have previously been reported. Two new cases are presented and long term follow up on the earlier cases is reported. Intraoperatively these tumours often have only a small area of attachment to the floor of the third ventricle and it is tempting to attempt to remove the tumour completely. In all cases the surgery was uneventful, yet postoperatively three of the five cases had significant morbidity, including memory deficits, diabetes insipidus, and abnormalities of central temperature control. The place of radiotherapy in the treatment of these tumours is discussed. ${ }^{2}$ It is concluded that attempts at total surgical excision should be approached with caution as significant long term morbidity can follow such surgery and that perhaps the better alternative is subtotal removal followed by radiotherapy.

1 Iwasaki K, Kondo A, Takahashi JB, Yamanobe of Intraventricular craniopharyngioma: report Neurol 1992;38:294-301.

2 Fischer EG, Welch K, Shillito J, et al. Craniopharyngiomas in children. Long term effects of conservative surgical procedures combined with radiation therapy. $\mathcal{F}$ Neurosurg [SBNS] 990;73:534-40.

BLOOD TRANSFUSION AND SURVIVAL FROM INTRINSIC SUPRATENTORIAL HIGH GRADE GLIOMAS

JD Palmer, RM Pickering, DW Ellison, DA Schilder, F Iannotti. Wessex Neurological Centre, Southampton, UK

Objectives-To measure the influence of blood transfusion on survival in patients with intracranial gliomas.

Design-Prospective data were examined from 175 patients who had entered EORTC glioma studies. Transfusion data were collected retrospectively from case records. Patients-All patients were over 16 years old, steroids had been stopped by the 10th postoperative day, survival was expected for more than eight weeks, and all had similar courses of radiotherapy.

Outcome measures-Survival was established by telephone interview of the next of kin.

Results-Hazard ratios of factors affecting survival were calculated by a series of Cox regression models. Variables significantly affecting survival were age $(P=0.0016)$, pathology $(P=0.0075)$, and tumour location $(P=0.0075)$. After adjustment, Karnovsky index, tumour resection, or adjunctive treatment had no significant effect on survival. Blood transfusion was a significant protective factor for glioblastoma with a hazard ratio of 0.38 ( $95 \%$ confidence intervals $0.22-0.67)$, had no effect for anaplastic astrocytoma $1.70(0.58-4.94)$, and was a risk factor for other pathologies $4.56(0.97-21 \cdot 35)$. The different risk between these groups is highly statistically significant $(P=0.0003)$.

Conclusions - In this group of patients transfusion improved survival from glioblastoma. Suppression of cell mediated immunity is known to occur in patients with glioblastoma similar to that seen in AIDS; further modulation by transfusion may play a part in improving survival.

[SBNS]
AN ECONOMIC ARGUMENT IN FAVOUR OF ENDOSCOPIC THIRD VENTRICULOSTOMY AS A TREATMENT FOR OBSTRUCTIVE

HYDROCEPHALUS

HS Ching, $\mathbf{P}$ Barlow. Southern General Hospital, Glasgow, UK

Objectives-To examine the health resource implications of performing endoscopic third ventriculostomy as an alternative to CSF shunting in appropriate patients.

Design-A retrospective study of case records and radiographs of patients shunted de novo at the Institute of Neurological Sciences, Glasgow for the two year period 1990-1.

Outcome measures-The number of repeat operations and extra days in hospital required due to shunt complications compared with the predicted extra operations and days in hospital for patients suitable for endoscopic third ventriculostomy.

Results-One hundred and fifty new shunts were inserted in the two years. Of these, 23 patients $(15 \%)$ were judged suitable for endoscopic third ventriculostomy as an alternative to CSF shunting. Eight out of 23 patients required a total of 29 repeat operations and an extra 230 days in hospital due to shunt complications. Assuming an $80 \%$ success (shunt free) rate for endoscopic third ventriculostomy, nine operations and 74 bed days per year could be saved by using this technique.

Conclusions-In units undertaking a large number of CSF shunt insertions, investment in neuroendoscopic equipment has the potential to release significant resources for other uses.

[SBNS]

VINCRISTINE AND CARBOPLATIN TREATMENT FOR PROGRESSIVE LOW GRADE

ASTROCYTOMA OF BRAIN

MS Ashraf, P May, H McDowell. Royal Liverpool Children's Hospital, Liverpool, UK

Five children (age range 4 months to 8 years and 4 months), with progressive low grade astrocytoma (grades I and II) were treated with weekly vincristine $\left(1.5 \mathrm{mg} / \mathrm{m}^{2}\right)$ and carboplatin $\left(500 \mathrm{mg} / \mathrm{m}^{2}\right)$, every three weeks. Response in terms of either reduction in tumour size or progression of disease, was achieved in all cases. The follow up period is 20 to 10 months (mean seven months). Initial response suggests combination chemotherapy with vincristine and carboplatin is effective in holding the disease and delaying the use of radiotherapy particularly in younger children.

[SBNS]

EVALUATION OF MICROENVIRONMENTAL HYPOXIA OF BRAIN TUMOURS: MODIFYING FACTORS

GS Cruickshank, R Duckworth. Institute of Neurological Sciences, Glasgow, UK

Objectives-To assess the impact of $\mathrm{PaCO}_{2}$ and blood pressure on oxygenation of human brain tumours at operation measured by dynamic stepping micropolarography and microlaser Doppler.

Design-The stratification of patients based on the oxygen profile of their intracranial 
tumours may allow assessment of the impact of chemical modifiers on radiation sensitivity. ${ }^{1}$ Characterisation of factors that influence intracranial tumour hypoxia, is therefore important. The question is whether the effect of altered arterial $\mathrm{PaCO}_{2}$ and blood pressure on cerebral blood flow and brain oxygenation devalue the significant level of hypoxia recorded in these tumours at operation.

Subjects-Twelve anaesthetised patients were ventilated at an $\mathrm{FiO}_{2}$ of $0 \cdot 25-0 \cdot 3$, and end tidal $\mathrm{CO}_{2}$ and $\mathrm{PaO}_{2}$ and $\mathrm{PaCO}_{2}$ were monitored. The Eppendorf $\mathrm{pO}_{2}$ histograph probe was used to measure $\mathrm{pO}_{2}$ profiles in tumours in these patients. Concurrently, microlaser Doppler flow measurements were made from brain, brain around tumour and tumour.

Outcome measures and results-Alteration in $\mathrm{pO}_{2}$ indices and variations in erythrocyte flux were assessed in response to a fixed change in $\mathrm{pCO}_{2}$ or mean arterial blood pressure; for reproducibility and reversibility of effect, altering the $\mathrm{PaCO}_{2}$ from $37 \mathrm{~mm} \mathrm{Hg}$ to 31 $\mathrm{mm} \mathrm{Hg}$ and back resulted in a reversible fall in median tumour $\mathrm{pO}_{2}$ of $4.2(0.4) \mathrm{mm} \mathrm{Hg}$, and in $\mathrm{pO}_{2}$ levels of less than $2.5 \mathrm{~mm} \mathrm{Hg}$ from $26.3 \%$ to $46.5 \%$. Changes in microregional blood flow (erythrocyte flux) recorded in the tumour, peritumoural area, and distant brain illustrate a pronounced impairment of reactivity in the peritumoural area. Conclusions-Altering $\mathrm{PaCO}_{2}$ has a reproducible impact on tumour $\mathrm{pO}_{2}$ that may be due to direct or shunting effects on cerebral circulation. The tumour $\Delta \mathrm{pO}_{2} / \triangle \mathrm{PaCO}_{2}$ seen is less than that for normal brain and does not overlap with tumour $\mathrm{pO}_{2}$ data from extracranial tumours, suggesting that hypoxia in intracranial tumours may be an important factor in their resistance to treatment. Multichannel microlaser Doppler techniques used in conjunction with tissue oxygen measurement allows the factors controlling tumour hypoxia to be evaluated and possibly manipulated therapeutically.

1 Rampling R, Cruikshank GS, Lewis AP, et al. Direct measurement of $\mathrm{pO}_{2}$ distribution and bioreductive enzymne brain tumours. 7 Radiat Oncol Biol Phys 1994;29:427-31. [SBNS]

SAFE NEUROSURGERY? AN AUDIT OF ACOUSTIC NEUROMA SURGERY IN A SMALI NEUROSURGICAL UNIT

PJ Kane, B Gendeh, M Hawthorne, FP Nath. Middlesbrough General Hospital and North Riding Infirmary, Middlesbrough, UK

Aims-To audit the results of acoustic neuroma surgery in a neurosurgical unit with small catchment population and compare with published standards of outcome.

Design-Retrospective study of 64 patients with acoustic neuroma operated on by a single neurosurgeon and neurootologist in the period 1986-94. All patients were operated on by the suboccipital retromastoid approach. Peroperative facial nerve monitoring became available in 1992. Specific audit points included referral pattern; mortality; postoperative CSF leak; postoperative facial nerve function at six months; and hearing preservation.

Results-Sixty nine per cent of patients were referred by otologists, the remainder from neurologists, general physicians, or general practitioners. Two patients (3\%) died after surgery. Both had large tumours $(>5.5 \mathrm{~cm})$.
Five patients (8\%) developed CSF leak that was treated operatively in four and by spinal drainage in one. All patients with small tumours $(<10 \mathrm{~mm}$ ) had good recovery of facial nerve function (those house grade I/II); $27 \%$ of patients with medium sized tumours (11-25 $\mathrm{mm}$ ), and $33 \%$ of patients with large tumours (>26 mm) had a facial palsy. Ten patients had some preserved hearing on the affected side at the time of their presentation. Postoperatively four were deaf, three had retained non-useful hearing, and three had retained useful hearing.

Conclusion-The results compare favourably with published data. Acoustic neuroma surgery can be performed safely in a small neurosurgical unit.

[SBNS]

COMPLICATIONS OF SKULL BASE GLOMUS SURGERY: 10 YEARS OF OTONEUROSURGICAL EXPERIENCE

PC Whitfield, DA Moffat, DG Hardy. Addenbrooke's Hospital, Cambridge, UK

Objectives-To review and evaluate the management and outcome in patients undergoing surgery for skull base glomus tumours. Design-Retrospective analysis of all patients with large skull base glomus tumours treated by combined otoneurosurgery during a 10 year period.

Subjects-Fifteen patients with glomus jugulare tumours, three patients with glomus vagale tumours, and one patient with a glomus hypoglossus.

Outcome measures - (a) Performance of additional procedures to treat post-operative complications. (b) Functional outcome on a disability scale at long term follow up.

Results-An infra/transtemporal approach $(n=15)$ for Fisch grade $C$ and $D$ tumours, or a tympanomastoid approach $(n=4)$ for Fisch grade $B$ tumours was performed. The facial nerve was transposed in 12 patients (63\%). Cranial nerves were necessarily transected in eight cases (42\%); in six of these preoperative signs of cranial nerve involvement were evident. Ten patients (53\%) underwent surgery to treat complications; teflon injection of vocal cord ( $n=5)$, tarsorrhaphy $(n=3)$, wound re-exploration $(n=$ 3 ), surgery for facial palsy $(n=2)$, thyroplasty $(n=2)$, ventriculoperitoneal shunt $(n=1)$, and squint surgery $(n=1)$. At long term follow up (mean 3.24 years) $68 \%$ of patients had an excellent functional outcome, $11 \%$ a good outcome, and $21 \%$ a fair outcome. Conclusions-Most patients with a preexisting lower cranial nerve palsy adapt to intraoperative cranial nerve transection extremely well. A multidisciplinary team is required to achieve optimal results in patients with these complex skull base tumours. [SBNS]

RADIOSURGERY/STEREOTACTIC

RADIOTHERAPY FOR SOLITARY BRAIN

METASTASES: A NON-INVASIVE ALTERNATIVE TO SURGERY

M Brada, RE Wurm, AP Warrington, RW Laing, S Sardell, F Hines, JD Graham. Royal Marsden Hospital and Institute of Cancer Research, London, UK

Fifty two patients with 57 solitary brain metastases (one to two lesions) were treated with stereotactic radiotherapy/radiosurgery (SRT) with or without whole brain irradia- tion (WBRT). Twenty nine patients received SRT as primary treatment. Twenty three patients were treated for recurrence after surgery and WBRT and after WBRT alone. The SRT dose was $20 \mathrm{~Gy}$ in two fractions in most patients prescribed to the $90 \%$ isodose. The target volume encompassed the enhancing tumour and a $2 \mathrm{~mm}$ margin.

Local progression free survival (PFS) was $61 \%$ at one year (27 months median PFS) and the median survival was seven months. Most patients had a functional improvement as measured by the Barthel index. Neurological deterioration was noted in two patients within one month of SRT.

The results of SRT in patients with solitary brain metastases in terms of local control and survival seem equivalent to neurosurgical excision; SRT is a useful palliative treatment-it is well tolerated, noninvasive, and outpatient based and is particularly of value in patients whose survival is determined by the systemic course of disease. The role of WBRT in combination with SRT remains to be defined. [SBNS]

INCIDENCE OF BRAIN METASTASES AND RELATION TO SYSTEMIC TUMOUR SITES R Grant, D Collie. Western General Hospital, Edinburgh, UK

There are no good epidemiological studies of brain metastases in the United Kingdom. The incidence of brain metastases in the Lothian region, the frequency of single metastasis and metastases of unknown primary, and the clinical relations with primary site were examined.

Incident cases of intracranial tumour $(1989+1990)$ in the Lothian region were identified by examining all CT reports from the three scanners that cover SE Scotland, supplemented by multiple cross referenced cancer registration and neurological databases. Case records were retrieved and patient data analysed.

One hundred and eighty four people with brain metastases were identified (incidence: $12 \cdot 6 / 100000$ pop/year). Brain metastases accounted for $46.5 \%$ of all intracranial tumours; $37 \%$ of brain metastases were single; $34 \%$ of patients had no history of systemic malignancy at neurological presentation and no systemic site was ever identified in $15 \%$ (27). Lung (104), breast (22), melanoma (14), GI tract (seven) and renal (four) were the most commonly identified primary sites. All patients with brain metastases from breast and GI tumours and 13 with melanoma, had a history of malignancy before neurological presentation. This provides useful clinical information for investigating patients with brain metastases. [ABN]

EFFECTS OF ARTERIOVENOUS

MALFORMATIONS ON CORTICAI

ORGANISATION: IMPLICATIONS FOR SAFETY OF RESECTION

GM McKhann II, JM Eskridge, DL Silbergeld, AB Harris, GA Ojemann, HR Winn. University of Washington, Seattle, USA

Objectives-Preoperative and intraoperative functional mapping can be used to identify the Rolandic and language cortex in patients 
with arteriovenous malformations (AVMs) near essential cortex. Using these techniques to facilitate safe excision of AVMs, the impact that these lesions have on cortical organisation has been studied.

Design-Utilising preoperative superselective amobarbital (WADA) testing and intraoperative stimulation mapping, the topographical organisation of functional cortex in patients with AVMs was investigated.

Patients-Thirty eight consecutive patients with AVMs near essential functional cortex were evaluated.

Results-Individual variability exists in the topographical location of sensory and motor cortex and of sites essential for language function in patients with AVMs. Most patients with AVMs reorganise functional cortex into atypical topographical configurations by displacing Rolandic and/or language cortex. Two patients were found to have motor cortex located within AVMs.

Conclusions-There is variability and plasticity of human cortical organisation in patients with AVMs. Most AVMs displace functional cortex and can potentially be safely resected. Preoperative superselective WADA testing and/or intraoperative stimulation mapping are recommended for lesions near eloquent cortex to determine those that may be unresectable.

[SBNS]

"DYNAMICS" OF INTRACRANIAL ANEURYSMS DEMONSTRATED BY COLOUR TRANSCRANIAL DOPPLER ULTRASOUND

JM Wardlaw, J Cannon. University of Edinburgh, Edinburgh, UK

It is possible to demonstrate intracranial aneurysms and AVMs using directionally sensitive conventional colour transcranial Doppler ultrasound (CDI), which has been available for several years. A recent development of colour Doppler technology "colour Doppler energy" (CDE) or "power Doppler" is considerably more sensitive to flowing blood. This technique has been applied to the detection of intracranial aneurysms in patients presenting with subarachnoid haemorrhage (SAH).

As many patients as possible presenting to our regional neurosurgical service with recent SAH (either CT or LP proved) were assessed by colour transcranial Doppler, using the temporal bone windows, blind to the result of angiography although not to the distribution of blood on CT.

Thirty nine patients have been examined so far (mean age 50), the first nine with CDI and the last 30 patients with CDE. Aneurysms were recognised as an area of colour where no normal artery was expected, and on CDE by apparently greater "pulsatility" than normal arteries during the cardiac cycle. CDE reduced the proportion of patients with a poor bone window $(10 \%$ with patients with CDI). CDE detected 26 of 29 aneurysms demonstrated angiographically $(90 \%)$, whereas CDI only detected $55 \%$. In five patients who underwent aneurysm coiling it was possible to see the coil being inserted into the aneurysm and to measure the residual neck with $\mathrm{CDE}$. The measure the residual nectional area between systole and diastole was $49 \%$ $( \pm 28 \%)$ and in the cross sectional area of an adjacent normal artery was $18 \%$ ( $\pm 20 \%$ ): mean of difference $-30.8 \%, 99 \%$ CI -60 to $-2 \%$. CDE is an appreciable improvement in colour TCD technology. Further evaluation is required to see whether aneurysm "pulsatility" could be used as an indicator of impending rupture.

[ABN]

SERUM LIPOPROTEIN (A) CONCENTRATIONS IN FAMILIAL CEREBROVASCULAR ANEURYSM C Bolger, JP Phillips. Beaumont Hospital, Dublin, Eire and Walton Hospital, Liverpool, UK

Objective-To investigate serum lipoprotein (a) $(\mathrm{Lp}(\mathrm{a}))$ concentrations in patients with familial cerebrovascular saccular aneurysms. Design-Case identification from family history of patients admitted with proved subarachnoid haemorrhage secondary to saccular cerebrovascular aneurysm. Patients with two or more first degree relatives with proved aneurysmal subarachnoid haemorrhage were recruited. They were screened with cerebral angiography and fasting serum Lp(a) was measured.

Patients - To date 15 patients (siblings) from two families have been identified (eight males and seven females, mean age 37.9 $(10 \cdot 2)$ years).

Outcome measures-Serum Lp(a) concentrations in relation to the presence or absence of saccular aneurysm.

Results-Four patients died from subarachnoid haemorrhage before enrolment into the study; one patient refused investigation. Of the remaining 10 patients: seven had asymptomatic aneurysms identified on cerebral angiogram. Six of these patients had serum $\mathrm{Lp}$ (a) concentrations above normal ( $>30$ $\mathrm{mg} / \mathrm{dl}$; mean (SD) $54.7(11.8) \mathrm{mg} / \mathrm{dl})$. Two patients had normal cerebral angiograms and the $\mathrm{Lp}(\mathrm{a})$ in both patients was normal (10 and $25 \mathrm{mg} / \mathrm{dl}$ ). In the remaining patient (with an $\mathrm{Lp}$ (a) concentration of $64 \mathrm{mg} / \mathrm{dl}$ ) angiography was incomplete.

Conclusions - There is evidence of an association between raised serum concentration of $\mathrm{Lp}$ (a) and cerebral aneurysms.

[SBNS]

A MAGNETIC RESONANCE SPECTROSCOPIC STUDY OF PARKINSONISM RELATED TO BOXING AJ Lees, CA Davie, Z Pirtosek, GJ Barker, DP Kingsley, DA Miller. Institute of Neurology, London, UK

Proton magnetic resonance spectroscopy, localised to the lentiform nucleus, was carried out in three exprofessional boxers who developed a parkinsonian syndrome, six patients with idiopathic Parkinson's disease and in six age matched controls. The three boxers all showed a pronounced reduction in the absolute concentration of $\mathrm{N}$-acetyl aspartate (NAA), compared with the patients with Parkinson's disease and the control group. This reduction is likely to reflect neuronal loss occurring in the putamen and globus pallidus, and supports the hypothesis that the extra pyramidal syndrome, which occurs in exboxers, is distinct from idiopathic Parkinson's disease. These findings will be related to the existing literature on post traumatic Parkinson's syndrome.

[ABN]
MPLEMENTATION OF HEAD INJURY GUIDELINES: WHERE ARE WE AFTER TWO CYCLES OF A REGIONAL AUDIT?

JD Pickard, S Jackson, J Addison, P Smielewski, HK Richards. University of Cambridge, Cambridge, UK

Guidelines for the management of head injuries have been widely adopted but may not be followed in practice. ${ }^{1}$ A criterion based audit was conducted in the eight district general hospitals of East Anglia to assess the quality of documentation, investigation, and care of patients with head injury.

First cycle (1 October 1992-31 March 1993) -4789 patients' notes (1458 admitted) were extracted and those that did not meet the guidelines were peer reviewed anonymously in each hospital. Documentation was poor (no record of GCS $52 \%, \mathrm{BP}$ $37 \%$, or skull radiograph $71 \%$ ). Failure at peer review for skull radiograph, admission and/or CT criteria was $12 \%$ (range 8-15\% between hospitals): under investigation $10 \%$, over investigation $2 \cdot 4 \%$.

Second cycle (1 December 1993-28 February 1994) - a structured head injury proforma

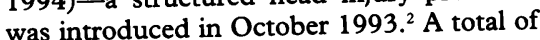
2718 notes ( 786 admissions) were audited and peer reviewed. Documentation improved by $37 \%$ to $89 \% \quad(P<0.001)$. Overall failure for skull radiograph, admission, and/or CT criteria was not significantly reduced ( $13 \%$; range $10 \%-19 \%)$. Overinvestigation was reduced from $2 \cdot 4 \%$ to $1.1 \%(P<0.001)$ but underinvestigation increased from $10 \%$ to $12 \%$ ( $P<0.001$ ).

Conclusion-Improvement in documentation and provision of a "structured" proforma have not yet improved the implementation of guidelines agreed by regional consensus.

1 Suggestions from a group of neurosurgeons. Guidelines for initial manageme

2 Wallace SA, Bennett J, Perez-Avila CA, Gullan $\mathrm{RW}$, et al. Head injuries in the accident and RW, et al. Head ine using emergency department: are we using Emergency Medicine 1994;11:25-31.

[SBNS]

ASSESSMENT OF THE GLASGOW HEAD INJURY OUTCOME PREDICTION PROGRAM

JJ Nissen, PA Jones, DF Signorini, JD Miller. Western General Hospital,

Edinburgh, UK

Objectives-To compare the predicted $v$ actual outcome after head injury using the Glasgow head injury prediction program, and to determine how often predictions were available.

Design-Retrospective data (1989-94) from 325 patients with severe head injury, haematoma requiring evacuation and/or coma >six hours, with Glasgow outcome scale (GOS) scores at six to 24 months follow up. The program calculates the probabilities of death/vegetative state (GOS 1 or 2), severe disability (GOS 3), or moderate disability/good recovery (GOS 4 or 5) on admission after severe injury, before evacuation of acute haematoma, or at 24 hours, three days, or seven days for those in coma. Results-Predictions were possible in $77 \%$ $96 \%, 19 \%, 34 \%$, and $53 \%$ of "suitable" patients at admission, operation, 24 hours, three days, and seven days respectively. Paralysis/ventilation meant that predictions were often unavailable, ranging from $15 \%$ of those "suitable" at admission, to $76 \%$ at 24 
hours. Seventy four per cent of predictions were correct (highest probability), $16 \%$ pessimistic, and $10 \%$ optimistic. Of those patients whose eventual outcome was either GOS $4 / 5$ or GOS $1,84 \%$ were correct; for those GOS 3, only $12 \%$ were correctly predicted. Of 64 pessimistic predictions, $48 \%$ were predicted to die or be vegetative, but actually achieved a moderate or good outcome. Conclusion-The Glasgow head injury prediction program can be a useful adjunct in clinical decision making in some head injured patients.

1 Murray LS, Teasdale GM, Murray GD, et al. Does prediction of outcome alter patient
management? Lancet 1993;341:1487-91. [SBNS]

OUTCOME IN CHILDREN WITH SEVERE HEAD INJURY: IMPORTANCE OF CEREBRAI PERFUSION PRESSURE

PJ Kane, IR Chambers, A Davidson, L Treadwell, NV Todd, A Jenkins, PJ Crawford, RP Sengupta, AD Mendelow. Newcastle General Hospital, Newcastleupon-Tyne, UK

Objectives-To determine what factors may be important in predicting outcome after severe head injury in children.

Design-Retrospective study of 50 children (age $\leqslant 16$ ) with a severe head injury (Glasgow coma score on admission to the neurosurgical unit $\leqslant 8$ ) who required intracranial pressure (ICP) monitoring as a routine part of their management. Mean arterial blood pressure, ICP, and cerebral perfusion pressure (CPP) were measured continuously. Outcome was determined at six months with the Glasgow outcome scale. Independent outcome is defined as those children who made a good recovery or were moderately disabled.

Results - Nine patients died. In the remainder the outcome scores at six months after injury were: seven severely disabled; 12 moderately disabled; 22 good recoveries. Glasgow coma score on admission, injury severity score, and average maximum ICP were not reliable predictors of outcome. As with a previous study, ${ }^{1}$ higher values of average minimum CPP were associated with better outcome: good recovery 58.5 (3.9) $\mathrm{mm} \mathrm{Hg}$; moderately disabled $58.4(2.5) \mathrm{mm}$ $\mathrm{Hg}$; severely disabled $44.5(4.3) \mathrm{mm} \mathrm{Hg}$; dead $45.3(16.2) \mathrm{mm} \mathrm{Hg}$. Average minimum CPP values $>50 \mathrm{~mm} \mathrm{Hg}$ were associated with a significantly greater chance of independent outcome $\left(\chi^{2} \mathrm{P}<0.05\right)$.

Conclusion-This study points to the importance of CPP as a determinant of outcome after severe head injury in children.

1 Mendelow AD, Allcut DA, Chambers IR, et al. In: Avezaat CJJ, et al, eds. ICV VIII. Berlin [SBNS] Springer Verlag 1993:544-8.

LABORATORY TESTING OF THREE INTRACRANIAL PRESSURE

MICROTRANSDUCERS

M Czosnyka, Z Czosnyka, JD Pickard.

University of Cambridge, Cambridge, UK

Three comparably priced ICP microtransducers have become available on the United Kingdom market, each characterised by their manufacturer as having very low zero drift over long periods, an excellent frequency response, and a low measurement error. The three microtransducers, coded A, B, and C, were examined in the pressure flow test rig designed for assessment of hydrocephalus shunts. All three microtransducers complied with their manufacturer's specifications, giving high quality readings under test conditions. Some differences were noted, however, 24 hour zero drifts were lower than 0.8 $\mathrm{mm} \mathrm{Hg}$ and $\mathrm{C}$ had the lowest. The temperature drift was very low in $B$ and $C$ but $A$ had a drift of $0.27 \mathrm{~mm} \mathrm{Hg} /{ }^{\circ} \mathrm{C}$; $\mathrm{A}$ had a static error of less than $0.3 \mathrm{~mm} \mathrm{Hg}, B$ of less than $2 \mathrm{~mm} \mathrm{Hg}$, and $\mathrm{C}$ of less than $8 \mathrm{~mm} \mathrm{Hg}$. The limits of the frequency response were not detectable in A and B (band width wider than $50 \mathrm{~Hz}$ ), whereas $C$ had a band width limited to $18 \mathrm{~Hz}$.

Conclusion-Transducer B scored the best overall but all three behave satisfactorily on bench testing. The use of each transducer in everyday clinical practice requires evaluation. [SBNS]

A PROSPECTIVE COMPARISON OF SUBDURAL FIBREOPTIC AND FLUID FILLED SINGLE LUMEN BOLT PRESSURE TRANSDUCERS IN VENTILATED PATIENTS

S Bavetta, JC Sutcliffe, P Chumas, OCE Sparrow, PJ Hamlyn. The Royal London Hospital and St Bartholomew's Hospital, London, UK

A clinical comparison was made between subdural fibreoptic and fluid filled subdural bolt pressure transducers in ventilated patients with head injury. Twelve patients had both devices inserted in neighbouring sites. In two patients there were obvious technical problems with the fibreoptic system and the results were therefore excluded from further analysis. In the remaining 10 patients 2167 pairs of simultaneous recordings were made for up to nine days and the degree of correspondence studied. A quarter of paired readings differed by more than $5 \mathrm{~mm} \mathrm{Hg}$. Neither device showed a predisposition to reading either higher or lower than the other, but in individual patients there was often a consistent bias. The proportion of closely corresponding readings tended to diminish after four days, and when either device registered a very high or low value. Clinically relevant episodes, defined as a reading of over $20 \mathrm{~mm} \mathrm{Hg}$ by only one of the two monitors, occurred 221 times with both systems equally likely to produce higher readings. Differences in treatment would be likelier if such values occurred on consecutive occasions, which happened, on average, about every 30 hours. The relative accuracy of the two devices remains uncertain, but there is evidence suggesting that both are prone to errors. [SBNS]

EVIDENCE OF SMALL VESSEL CHANGES CAUSING ISCHAEMIA AFTER SUBARACHNOID HAEMORRHAGE

JG Rowe, N Soper, R Ouwerkerk, RSC Kerr, B Rajagopalan. MRC Spectroscopy Unit and the Radcliffe Infirmary, Oxford, UK

Objective-To follow cerebral blood flow (CBF) with single photon emission computed tomography (SPECT), metabolism with phosphorus magnetic resonance spectroscopy, and vasospasm with angiography and transcranial Doppler (TCD), in a 62 year old woman with subarachnoid haemorrhage from a right middle cerebral artery (MCA) aneurysm.

Results-On day 3, she was well. Spectroscopy on the right showed acidosis (pH 6.35 ) suggesting anaerobic metabolism, but was normal contralaterally ( $\mathrm{pH} 7 \cdot 01$, control mean 7.02 (SD 0.01). On day 6, she became drowsy and confused. Spectroscopy showed decreased high energy phosphates, suggesting cell death. SPECT showed pronounced hypoperfusion of the right frontal lobe (CBF relative to cerebellum 0.58 (SD 0.03) right, 0.87 (SD 0.02) left). There was no TCD evidence of vasospasm (right MCA velocity 43 (SD 1) cm/s, left 35 (SD 2, controls 58 (SD 2). Angiography (day 7) did not show vasospasm.

Aneurysm clipping was complicated by rebleeding, and postoperatively by vasospasm (MCA velocity $>120 \mathrm{~cm} / \mathrm{s}$ ). A recovery SPECT (day 25) showed hyperaemia $(0.98$ (SD 0.03) in the right frontal lobe. Conclusions-Angiography and TCD only examine large and medium sized arteries. The SPECT finding of hypoperfusion, later reversing, without angiographic vasospasm, suggests that there may be changes in small vessels beyond angiographic resolution. The existence of such changes could explain discrepancies between ischaemia and angiographic vasospasm complicating subarachnoid haemorrhage. [SBNS]

FAMILIAL HEMIPLEGIC MIGRAINE AND THE AGE RELATED SPECTRUM OF CEREBRAI AUTOSOMAL DOMINANT ARTERIOPATHY LINKED TO CHROMOSOME 19

M Hutchinson, J O'Riordan, $M$ Javed, E Quin, T Willcox, N Parfrey, D Macerlaine, TG Nagy, E Tournier-Lasserve. St Vincent's Hospital, Dublin, Eire, and Inserm U25, Paris, France

Cerebral autosomal dominant arteriopathy with subcortical infarcts and leucoencephalopathy (CADASIL) is a recently described familial cerebrovascular disorder which has been shown to map to chromosome 19q12. Familial hemiplegic migraine has also been shown to be linked to chromosome 19 close to the CADASIL locus. The CADASIL phenotype is defined, as a minimum, by brain MRI abnormalities in an at risk family member. By this criterion 10 of 15 fully investigated members of a large Irish family had CADASIL. Brain MRI showed a leucoencephalopathy of varying severity. The spectrum of presenting features included familial hemiplegic migraine, common and classical migraine, transient cerebral ischaemic attacks, recurrent strokes, and spinal cord infarction. One family member was asymptomatic; two members developed a pseudobulbar palsy and subcortical dementia. In five familial hemiplegic migraine started in childhood and four of these have subsequently developed the features of CADASIL. Familial hemiplegic migraine has not been reported in association with CADASIL. Linkage analysis showed significant lodscores (3.91 with D19S226) with markers close to the locus for the CADASIL gene. We postulate that familial hemiplegic migraine is, in this 
family, a manifestation of the CADASIL gene inheritance, which may produce variable, age related clinical manifestations. [ABN]

WHICH METHOD OF MEASUREMENT SHOULD BE USED TO ASSESS CAROTID ANGIOGRAMS? GR Young, PRD Humphrey, TE Nixon, ETS Smith. Walton Centre for Neurology and Neurosurgery, Liverpool, UK

In future, non-invasive techniques will obviate the need for digital subtraction angiography (DSA) in the assessment of extracranial internal carotid artery stenosis. There is currently much debate concerning which measuring technique to adopt when assessing the degree of carotid stenosis from angiograms. Using both DSAs and magnetic resonance angiograms (MRAs), four different methods-the "ECST", the "NASCET", the "common carotid artery as denominator" and the visual impression ("eyeballing") methods-were assessed and their reproducibility determined. One hundred and ten DSAs and 74 MRAs were assessed using all four methods by two independent observers on two separate occasions. Measurements were made using vernier scale calipers. The mean (SD) of the differences were calculated for each method (the smaller the SD the better the agreement).

For DSA, the mean (SD) of the differences between observers were: ECST, 6.4 (8.9)\%, NASCET, 9.6 (21.3)\%; common carotid, $6 \cdot 5(13 \cdot 8) \%$, eyeballing, $0 \cdot 1(10 \cdot 7) \%$ respectively. The consistency improved by each technique as the degree of stenosis increased. Similar results were obtained for MRA and intraobserver agreement.

Using calipers, the ECST and the common carotid techniques show least variation in reporting. The NASCET technique seems the least reproducible. Interestingly, eyeballing is a highly reproducible technique. [ABN]

ACE GENE POLYMORPHISM, CEREBROVASCULAR DISEASE, AND CAROTID ATHEROMA

H Markus, J Barley, S Jeffery, R Lunt, JM Bland, N Carter, MM Brown. King's College School of Medicine and Dentistry and St George's Hospital Medical School, London, UK

The molecular basis of the genetic predisposition to stroke is largely unknown. A deletion polymorphism in intron 16 of the ACE gene has been reported as an independent risk factor for myocardial infarction although the mechanism of this effect remains unknown.

With the polymerase chain reaction the insertion-deletion polymorphism was determined in 101 white patients (mean age 64.8) and 137 age matched controls (mean age 63.9). All patients presented with a carotid territory acute ischaemic event and carotid duplex was performed to assess degree of internal carotid artery stenosis and common carotid artery intima-media (IM) thickness. Plasma ACE concentrations were measured.

The DD genotype was commoner in patients with cerebrovascular disease than in controls (36/101 v 30/137, $\mathrm{P}=0.02)$ ). D:I allele frequency was $0.59: 0 \cdot 41$ in cases and $0.48: 0.52$ in controls $(P=0.01)$. The DD genotype conferred a relative risk of cerebrovascular disease of $2.4 \quad(95 \%$ CI $1 \cdot 14-5 \cdot 05 ; P=0 \cdot 02)$. The relation was independent of age, sex, smoking history, diabetes, or cholesterol but seemed to be mediated at least in part through hypertension. Neither the DD genotype nor the $D$ allele was positively associated with carotid stenosis or intima-media thickness.

The DD genotype is a new risk factor for cerebrovascular disease. It seems to exert its action at least partly through hypertension in this age group, although not via extracranial large vessel disease. In view of the lack of association with carotid artery wall thickness and stenosis it may act via small vessel disease, altered functional vessel responses, or by predisposing to cardiac disease. [ABN]

CONTINUED ISCHAEMIC DAMAGE AFTER CEREBRAL INFARCTION IN HUMANS DE Saunders, FA Howe, A van den Boogaart, MA McLean, JR Griffiths, MM Brown. St George's Hospital Medical School, London, UK

The aim was to study the ischaemic penumbra in humans, by measuring metabolic changes after middle cerebral artery territory (MCA) infarction using proton magnetic resonance spectroscopy ( ${ }^{1} \mathrm{H}-\mathrm{MRS}$; $1.5 \mathrm{~T}$ system). Localised ${ }^{1} \mathrm{H}-\mathrm{MRS}$ was carried out within the area of infarction and contralateral hemisphere. Peak areas were obtained by variable projection time domain fitting analysis. The unsuppressed water signal was used as internal concentration standard. Ten patients with acute MCA territory infarction were studied within 28 hours of stroke and for three months. Significant changes were seen in the initial infarct spectra compared with the contralateral spectra (table 1). Lactate, a marker of anaerobic metabolism, was detected within the infarct but not in the contralateral hemisphere. $\mathrm{N}$-acetyl aspartate (NAA), a neuronal marker, and total creatine $(\mathrm{Cr} / \mathrm{PCr})$ were significantly reduced. Further reductions in NAA and $\mathrm{Cr} / \mathrm{PCr}$ occurred within the first week (table 2). A fall in lactate was seen within the infarct core over the first seven to 10 days.

In conclusion, neuronal loss is detected non-invasively by ' $\mathrm{H}$-MRS within 28 hours of stroke onset. The continuing loss of neurons may represent continued ischaemic damage after MCA infarction.

[ABN]

STATUS DYSTONICUS ET RIGIDITUS: A REPORT OF 10 CASES

H Manji, RS Howard, NP Hirsch, DH Miller, L Carr, NP Quinn, CD Marsden. National Hospital for Neurology and Neurosurgery and Great Ormond Street Hospital for Sick Children, London, UK

Patients with primary and secondary dystonic syndromes may develop increasingly frequent and severe episodes of generalised dystonia and rigidity, which may be refractory to conventional drugs and, in severe cases, result in bulbar and ventilatory compromise.

Ten cases (mean age 21.4 (range 6-39) years) are presented. The diagnoses were athetoid cerebral palsy (three), posttraumatic dystonia (three), postencephalitic hemidystonia (one), relapsing/remitting dystonia-parkinsonism (one), infantile striatal necrosis (one), and myoclonic dystonia (one). Possible precipitating factors included infection (one) and starting clonazepam (two). Eight patients were ventilated for a mean period of 61 (range 7-300) days. The indications for ventilation were bulbar (four), respiratory (five), exhaustion (eight), and metabolic disturbance as a result of rhabdomyolysis (one).

Drug treatment used included benzhexol, tetrabenazine, pimozide, baclofen (oral and intrathecal), chlorpromazine, and carbamazepine. One patient improved with benzhexol and another with tetrabenazine. Two patients underwent thalamotomy-bilateral (no improvement); unilateral (improved). Two patients died, four returned to their prestatus condition, two improved partially, and two eventually recovered.

Thus patients with status dystonicus et rigiditus should be managed in intensive care units; standard drug treatment may be beneficial; paralysis and ventilation may be of benefit and the prognosis is guarded, partly depending on the underlying condition. [ABN]

ABNORMAL MOTOR UNIT SYNCHRONISATION BETWEEN ANTAGONIST MUSCLES IN DYSTONIA

SF Farmer, G Sheean, JC Rothwell, CD Marsden. Institute of Neurology, London, UK

Activity in networks of neurons that provide common presynaptic input to motoneurons produces synchronisation of motor unit discharges. Cross correlation of EMGs from pairs of synergistic muscles in humans may

Table 1

\begin{tabular}{|c|c|c|c|}
\hline Initial data (day 1) & Contralateral $(n=7)$ & Infarct $(n=10)$ & $P$ value ( $t$ test) \\
\hline $\begin{array}{l}\text { NAA }(\mathrm{mmol} / \mathrm{l}) \\
\mathrm{Cr} / \mathrm{PCr}(\mathrm{mmol} / \mathrm{l}) \\
\text { Cho }(\mathrm{mmol} / \mathrm{l}) \\
\text { Lactate }(\mathrm{mmol} / \mathrm{l})\end{array}$ & $\begin{array}{l}14 \cdot 7(1 \cdot 6) \\
11 \cdot 6(1 \cdot 0) \\
2 \cdot 1(0 \cdot 3) \\
0\end{array}$ & $\begin{array}{r}8.8(4 \cdot 3) \\
9 \cdot 4(2 \cdot 9) \\
1.9(0.5) \\
19 \cdot 2(0.5)\end{array}$ & $\begin{array}{l}<0.001 \\
<0.05 \\
\text { NS } \\
<0.001\end{array}$ \\
\hline
\end{tabular}

Table 2

\begin{tabular}{|c|c|c|c|}
\hline Infarct & Value day $1(n=7)$ & Value 7 days $(n=7)$ & $P$ value ( $t$ test) \\
\hline $\begin{array}{l}\text { NAA }(\mathrm{mmol} / \mathrm{l}) \\
\text { Cr/PCr }(\mathrm{mmol} / \mathrm{l}) \\
\text { Cho }(\mathrm{mmol} / \mathrm{l}) \\
\text { Lactate }(\mathrm{mmol} / \mathrm{l})\end{array}$ & $\begin{array}{rr}10.6 & (3 \cdot 4) \\
10.5 & (2 \cdot 6) \\
1.8 & (0 \cdot 6) \\
16.9 & (9 \cdot 3)\end{array}$ & $\begin{aligned} 6 \cdot 1 & (4 \cdot 1) \\
4 \cdot 4 & (2 \cdot 8) \\
1 \cdot 7 & (0 \cdot 7) \\
11 \cdot 4 & (7 \cdot 2)\end{aligned}$ & $\begin{array}{l}<0.05 \\
<0.01 \\
\text { NS } \\
\text { NS }\end{array}$ \\
\hline
\end{tabular}

Values for tables 1 and 2 are means (SD). 
show motor unit synchronisation and thus common presynaptic input. By contrast, antagonist motoneurons - for example, flexor and extensor carpi radialis (FCR/ECR)-do not produce synchronised discharges even when a subject deliberately cocontracts the muscles.

Dystonia is characterised by involuntary cocontraction of antagonist muscles. One hypothesis concerning abnormal muscle cocontraction in dystonia is that it is produced by abnormal common presynaptic input to motoneurons of antagonist muscles. Five patients with dystonia were studied (two idiopathic, three symptomatic, four women, ages 17-60). Simultaneous multiunit EMGs were recorded using concentric needle electrodes inserted into FCR and ECR, while patients cocontracted the muscles. For comparison, identical recordings were obtained from four healthy subjects (three men, ages 28-33). The times of motor unit occurrence from FCR and ECR were cross correlated. Cross correlograms of the healthy subjects were flat. Those of dystonic subjects contained a peak at time zero (median size $\mathrm{k}=$ 1.6 ; median duration $=38 \mathrm{~ms}$ ), indicating abnormal motor unit synchronisation.

It is concluded that in dystonia antagonist motoneurons share abnormal common presynaptic inputs. Activity of these inputs may produce abnormal muscle cocontraction. [ABN]

EMG GUIDED TREATMENT OF TASK SPECIFIC DYSTONIA WITH BOTULINUM TOXIN A GL Sheean, NMF Murray, AJ Lees, CD Marsden. National Hospital for Neurology and Neurosurgery, London, UK

The role of EMG in selection and placement of injections of botulinum toxin (BTX-A) in the treatment of limb dystonia is ill defined. EMG guided injections of Dysport $®$ BTX-A were used to treat 37 patients with task specific dystonia, 30 with writer's cramp (14 simple, 16 dystonic), five with primary writing tremor and two with musician's dystonia. After clinical inspection during the relevant task, likely active muscles were sampled with a teflon coated, 23G monopolar needle which allowed simultaneous EMG recording and injection. Usually two or three, but up to six, muscles were treated in each session. Commonly injected muscles included the wrist flexors/extensors, thumb and deep finger flexors, and index finger extensors. Initial doses ranged from $20-80 \mathrm{MU}$ and follow up was from 1-60 months. Initial evaluation and treatment generally took 45-60 minutes and up to 30 minutes at follow up. Subjective improvement occurred in $86 \%$ of patients (good to excellent in $76 \%$ ). Four showed no benefit. Significant weakness developed in nine and involved an adjacent, non-injected muscle in one case. EMG is essential for accurate identification of target muscles (both before and after BTX-A) and is particularly important for muscle selection in tremor.

[ABN]

\section{PRIMARY WRITING TREMOR}

PG Bain, LJ Findley, TC Britton, MA Gresty, JC Rothwell, PD Thompson, CD Marsden. MRC Human Movement and Balance Unit, London, UK

The clinical and neurophysiological features of 21 patients with primary writing tremor (PWT) are described. This was first described by Rothwell, et al (1979). Subsequently there has been controversy as to whether PWT is a forme fruste of essential tremor or a variant of writer's cramp.

Twenty one patients with PWT were studied using surface polymyography and accelerometry. Seven had a family history of PWT. In 13 patients the forearm reciprocal inhibition curve of the median nerve $\mathrm{H}$ reflex was also examined. The results of reciprocal inhibition were compared with those of 10 normal controls and to those obtained from patients with writer's cramp.

The median frequency of PWT was 5.5

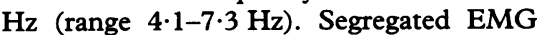
activity was typically alternating in forearm flexor/extensor pairs but co-contraction, extensor activation alone and varying EMG patterns were also recorded. Forearm reciprocal inhibition was normal in PWT. The patients were subclassified on clinical grounds into type A (task induced) and type B (positionally sensitive) PWT. The only differences between these two groups were that cocontracting tremor and tremor induced by tendon taps to the volar aspect of the wrist occurred in type B but not type A cases. Dominant hand writing speed was significantly reduced in PWT compared with age matched controls (PWT 73.1 letters/min; controls 138.8 letters $/ \mathrm{min}(\mathrm{P}<0.0001)$.

It is concluded that patients with PWT can be distinguished from writer's cramp as both the disynaptic and presynaptic phases of reciprocal inhibition are normal in PWT whereas the amount of presynaptic inhibition is decreased in writer's cramp; PWT can also be differentiated from hereditary essential tremor on clinical criteria. [ABN]

ADHESION MOLECULES IN AXO-GLIAL INTERACTIONS

CE Shaw, R Milner, C ffrench-Constant, DAS Compston. University of Cambridge, Cambridge, UK

With recent advances in immunotherapy for multiple sclerosis (MS) the possibility exists for promoting remyelination by endogenous or transplanted oligodendrocytes. The molecular mechanisms regulating axo-glial interaction in developmental myelination and repair are largely unknown. To study the role of the adhesion molecules, myelin associated glycoprotein (MAG), and integrins in mediating this interaction an in vitro model of myelination co-culturing rodent sensory neurons and glia has been used. The regional expression of MAG by oligodendrocytes is under axonal influence and MAG protein binds to axons confirming a specific ligand interaction. MAG expression occurs after the initial recognition and ensheathment takes place and blocking antibodies do not inhibit myelin formation, suggesting that MAG plays only a minor part in myelination. Integrins are heterodimeric adhesion molecules, composed of $a$ and $\beta$ subunits that recognise specific molecules in the extracellular matrix. With immunoprecipitation of cross species co-cultures $\alpha 6 \mathrm{~A} \beta 1$ and $a v \beta 5$ were greatly upregulated during myelination, suggesting that they may have a role in mediating this event. With a better understanding of the molecular mechanisms that control myelination it is hoped that treat- ments can be developed which enhance endogenous or transplanted oligodendrocyte repair.

[ABN]

IS THE VARIATION IN PREVALENCE OF MULTIPLE SCLEROSIS WITHIN THE UNITED KINGDOM DUE TO MIGRATION, LATITUDE, OR GENES?

PM Rothwell. Western General Hospital, Edinburgh, UK

There is debate about the extent to which the worldwide latitudinal gradient in the prevalence of multiple sclerosis is due to genetic or environmental factors. Northern Scotland has the highest prevalence in the world. Recent findings of high rates in southern England, however, have cast doubt on the assumption of a latitudinal gradient within the United Kingdom. To assess this a prevalence study was performed in south east Scotland. In addition, as susceptibility to multiple sclerosis seems to be either inherited or determined in childhood, mortality from multiple sclerosis within England and Wales was analysed by place of birth as well as place of death to detect any confounding due to migration.

Between 1969 and 1974 all deaths registered in England and Wales were linked with birth records. Place of birth and normal residence before death were obtained for the 3151 deaths in which multiple sclerosis was a cause and analysed within the nine standard regions. There was no latitudinal gradient by place of death, but the proportion of patients born outside the region in which they died was higher in southern regions $(41 \%-63 \%)$ than northern regions $(8 \%-18 \%)$. $\mathrm{Re}$ analysis by place of birth, however, still failed to show a latitudinal gradient within England. There were fewer than expected deaths of people born in Wales (observed expected $=0.64,95 \% \mathrm{CI}=0.54-0.75)$. The preliminary prevalence rate of multiple sclerosis in the Lothian and Border regions of Scotland (population 850 000) was in excess of $200 / 100000$. This is similar to rates in northern Scotland and significantly higher than the rates in southern England. These data suggest that there is no latitudinal gradient within either England or Scotland, but that there are differences in the prevalence of multiple sclerosis between England, Scotland, and Wales. This most probably reflects the genetic susceptibility of the respective populations.

$[\mathrm{ABN}]$

SERIAL BRAIN AND SPINAL CORD MRI IN MULTIPLE SCLEROSIS

JW Thorpe, D Kidd, IF Moseley, BE Kendall, WI McDonald, DH Miller. Institute of Neurology, London, UK

The dynamics of multiple sclerosis have been extensively studied by serial MRI of the brain; less is known about the spinal cord. Monthly gadolinium-enhanced brain and spinal cord MRI over a period of one year were carried out in 10 patients with relapsing-remitting multiple sclerosis. Six patients had a total of 11 clinical relapses of which eight implicated the spinal cord. One hundred and sixty seven active (enhancing or new non-enhancing) lesions were detected in 
the brain, of which only one was symptomatic; conversely six of the 19 active spinal cord lesions found were symptomatic. All but seven of the active lesions were in the six patients who relapsed. Both cord and brain activity were more common around the time of relapse. There was a strong association between the cord and brain MRI activity. No progressive cord atrophy was detected from measurements of cord cross sectional area.

In relapsing-remitting multiple sclerosis, therefore, imaging the brain alone will detect $90 \%$ of active lesions. The lack of progressive cord atrophy, suggesting that significant axonal loss has not occurred, is in keeping with their good recovery after relapse: this contrasts with our previous findings in progressive multiple sclerosis in which increasing cord atrophy developed whereas active lesions were rare in the absence of superimposed relapses. The concurrence of brain and spinal cord lesions implies a systemic trigger for disease activity. [ABN]

DAILY URINARY NEOPTERIN EXCRETION AS AN IMMUNOLOGICAL MARKER OF DISEASE ACTIVITY IN MULTIPLE SCLEROSIS G Giovannoni, M Lai, DH Miller, JW Thorpe, D Kidd, AJ Thompson, G Keir, EJ Thompson. Institute of Neurology, London, UK

The excretion of neopterin, a marker of macrophage activity in patients with multiple sclerosis was investigated. Daily urinary neopterin:creatinine ratios (UNCR) were measured by high performance liquid chromatography for a 12 week period in eight controls, eight patients with non-relapsing progressive, and nine patients with relapsing multiple sclerosis. Infection, relapses, day to day fluctuations in neurological function and Gd enhanced MRI were monitored.

The mean UNCR was significantly higher in patients with non-relapsing progressive (191 (86) $\mu \mathrm{mol} / \mathrm{mol}$ ) and relapsing disease (558 (652) $\mu \mathrm{mol} / \mathrm{mol}$ ) compared with controls (119 (28) $\mu \mathrm{mol} / \mathrm{mol}, \mathrm{P}=0.001)$. One asymptomatic peak in the serial UNCRs was found in one control subject compared with an average $2.2(2.3)$ peaks/patient/month in non-relapsing progressive and 3.2 (1.3) peaks/patient/month in patients with relapsing multiple sclerosis $(P=0.002)$; two peaks were temporally associated with a clinical relapse and clearly defined peaks and elevations in the baseline were noted around 21 days after an upper respiratory tract infection in three patients. Patients with day to day fluctuations in neurological function had higher mean UNCR than patients without (526 (624) $v 182$ (69) $\mu \mathrm{mol} / \mathrm{mol}, \mathbf{P}=0.05$ ). Mean UNCRs tended to be higher in patients with MRI activity than patients without activity (512 (631) $v 203$ (84) $\mu \mathrm{mol} /$ mol, NS).

Neopterin seems to be a promising immunological marker that can detect subclinical inflammation in patients with multiple sclerosis.

[ABN]

MULTIPLE SCLEROSIS: RECURRENCE RISKS FOR RELATTVES

N Robertson, J Deans, $M$ Fraser, DAS
Compston. University of Cambridge, Cambridge, UK

Familial recurrence risks in multiple sclerosis are becoming of increasing interest to geneticists in search of disease susceptibility genes and to clinicians who counsel patients. Little contemporary information is available for the United Kingdom, the population of which continues to exhibit an overall trend of increasing prevalence and incidence; rates derived from genetically and geographically distant populations may not be relevant. In addition crude risks, which have previously been used, may be misleading in younger populations because of the widely distributed age at onset profile of multiple sclerosis. The personal details and disease status have been systematically recorded for more than 11000 relatives of 650 probands with probable or definite disease listed on the Cambridgeshire Multiple Sclerosis Register and prevalent on 1 July 1993 to provide crude and age adjusted recurrence risks for first, second, and third degree relatives. Maximal crude risks were found for sisters of female probands (5\%) and age adjusted risks for female offspring of male probands $(7 \%)$. Risk was found to fall proportionately with genetic distance from the proband but was still significantly raised in first cousins $(1 \cdot 0 \%)$ compared with background prevalence $\left(132 \times 10^{5}\right)$ suggesting that the phenomenon of familial aggregation in multiple sclerosis is likely to depend on genetic factors.

[ABN]

DO CELLS FROM THE ADULT HUMAN BRAIN HAVE REMYELINATING POTENTIAL?

DAS Compston, NJ Scolding, J Sussman, CE Shaw. University of Cambridge, Cambridge, UK

Limited remyelination of some multiple sclerosis lesions is known to occur but recurrent lesions lead to permanent demyelination and disability. Advances in immunotherapy may arrest the inflammatory process and the real possibility exists for repairing areas of demyelination in an immunologically stable environment. Possible strategies for repair include promoting endogenous remyelination or transplantation of cells with myelinating potential. To determine which oligodendrocytes derived from adult human brain have remyelinating potential, their interaction with neuronal cultures was studied in vitro. Embryonic rat dorsal root ganglion neurons were purified in culture and cells dissociated from human temporal lobe white matter were added. Co-culture with axons improved oligodendrocyte survival but did not lead to proliferation. Within one week oligodendrocyte precursors were extending processes along axonal bundles and by four weeks there was extensive ensheathment of axons by membranes positive for myelin basic protein. After six weeks, there were loose wraps of myelin around axons by transmission electron microscopy but compact myelin was not detected. This confirms that isolated adult human oligodendrocytes can correctly identify exposed axons as the target for ensheathment but species barriers may exist in this model that prevent compact myelin formation. This attempt at remyelination by human oligo- dendrocytes in vitro is encouraging for the prospects of repair in multiple sclerosis. [ABN]

CREATION OF COMPOSITE DATA SETS FOR USE WITH THE ISG IMAGE DIRECTED SURGICAL SYSTEM

PR Eldridge, JN Roberts, RHT Edwards. Walton Centre for Neurology and Neurosurgery and the University of Liverpool, Liverpool, UK

Computed tomography and MRI provide information concerning anatomy, pathology, and function of the brain. Many data sets are created for a single patient. Image directed systems enable accurate surgical localisation from these data sets. Unfortunately the ISG image directed system only utilises a single data set at a time. It would be desirable to make use of information from more than one data set in surgery; such as different $M R$ sequences, or combinations of MRI and CT

A method combining data sets for the ISG system is illustrated, using the image analysis program "analyze". Raw CT and MRI data are transferred to "analyze" using XDimage. Features of importance are segmented in each data set. The data sets are combined and returned to the ISG system for surgery. This process requires close involvement of the operating surgeon.

The technique has wide application. Examples shown include intrinsic tumours, acoustic neuroma; pituitary tumours, caroticocavernous fistulas (utilising MR angiography). Bony detail, best obtained from CT, can be combined with data concerning tumours best seen on MRI (acoustic, pituitary, cavernoma, base of skull tumours). The method compensates for the geometric distortion of MRI data sets, which can result in inaccuracy twice as great as when using CT. [SBNS]

EMBOLISATION OF INOPERABLE

INTRACRANIAL ANEURYSMS BY

ENDOSACCULAR PACKING WITH PLATINUM COILS

J Byrne, A Molyneux, R Kerr, P Brennan, A Hope, S Renowden. Radcliffe Infirmary, Oxford, UK

Over a 30 month period 154 patients were referred for endovascular treatment of inoperable intracranial aneurysms. Patients were judged unsuitable for surgical clipping, being unfit for craniotomy because of the aneurysm's size, location, and wall thickness. Six patients were not treated by the endovascular route because of unsuitable anatomy and 18 patients were treated for additional coincidental aneurysms. A total of 164 aneurysms were therefore treated in 173 procedures using Guglielmi detachable coils (Target Therapeutics). Most patients presented with subarachnoid haemorrhage $(74 \%)$ and over $70 \%$ were treated within three weeks of the ictus. Forty five per cent of aneurysms were on vertebrobasilar arteries.

The aneurysms were packed with multiple electrolytically detached coils to form stable intraluminal thrombus and all patients have been offered follow up angiography at six months. Procedural complications have included aneurysm rupture and coil fractures 
but the most common adverse event has been the formation of thromboemboli. As a result anticoagulants are now given during and for up to 48 hours after treatment.

The overall morbidity (permanent deficit) was $5 \%$ and mortality $4 \%$. Complications occurred with similar frequency in the anterior and posterior circulations. [SBNS]

POSTERIOR CIRCULATION ANEURYSMS: TO COIL OR CLIP?

KW Lindsay, E Teasdale, $\mathbf{P}$ Mathew. Institute of Neurological Sciences, Glasgow, UK

Objective-To determine the optimal management of patients with posterior circulation aneurysms.

Design-All patients with posterior circulation aneurysms undergoing treatment by either direct clipping or by coil embolisation were reviewed over a five year period from 1989 to 1994.

Patients-Of 76 patients included in the study, 66 underwent direct clipping and 10 underwent coil embolisation.

Outcome measures-Aneurysm features (size, direction of fundus, neck height, and width). Outcome as assessed by the Glasgow outcome scale. Complications during coiling and occlusion rate.

Results-Of 66 patients undergoing operative clipping, $60(90 \%)$ made a favourable outcome; three patients died. In five of the six patients making an unfavourable outcome (severe disability or death), the aneurysm lay at the basilar bifurcation. Aneurysm features did not seem to relate to outcome.

In 10 patients, 32 coil embolisation procedures were performed. Two patients re-bled during coiling, of whom one died. Inadvertent placement occurred in four patients, but only one developed a neurological deficit. Complete occlusion was achieved in two patients and $>90 \%$ occlusion in four. Revascularisation occurred on three occasions.

Conclusions-Coil embolisation is not performed without some risk. The long term effects of incomplete occlusion remain unknown. Use should be restricted to technically difficult aneurysms, particularly those at the basilar bifurcation.

[SBNS]

NEUROPEPTIDE CONCENTRATIONS IN HUMAN CEREBRAL ARTERIES

L Chadwick, P Milner, G Burnstock, PJ Hamlyn. St Bartholomew's Hospital, and University College, London, UK

Objectives-To document the concentrations of neuropeptide Y (NPY), vasoactive intestinal polypeptide (VIP), substance $P(S P)$, and calcitonin gene related peptide (CGRP) in several arteries of the Circle of Willis in humans and to determine whether there is any change in the concentrations with postmortem delay.

Design-Documentation and comparison between neuropeptide concentrations in the middle and posterior cerebral arteries and the middle cerebral trifurcation.

Subjects-Twenty nine male and 18 female control cadavers (mean age $73.8(1.71)$ years and mean postmortem delay $27.91(1.41)$ ) hours.
Outcome measures-Concentrations of NPY, VIP, SP, and CGRP measured by enzyme linked immunosorbent assay and expressed as $\mathrm{pmol} / \mathrm{g}$ tissue.

Results-Neuropeptide concentrations were significantly higher in the middle cerebral artery compared with the posterior cerebra artery (NPY $13.53(2.85)$ v 7.18 (1.39), $\mathrm{P}<0.05$; VIP $13.72(2.93) v 3.34(0.77)$ $\mathrm{P}<0.01$; SP $8.83(1.43)$ v $1.23(0.46)$, $\mathrm{P}<0.001$; CGRP 26.93 (3.02) v 2.12 $(0.32), P<0.001)$. There was no difference between the concentrations in the middle cerebral artery compared with its trifurcation. There was no correlation between neuropeptide concentrations and either age or postmortem delay.

Conclusion-Neuropeptide concentrations are consistently higher in the middle cerebral artery than in the posterior cerebral artery in humans. The concentrations are stable and independent of postmortem delay. Postmortem cerebral vessels are thus suitable for comparative studies of neuropeptide concentrations in disease. [SBNS]

PEROPERATIVE MEASUREMENT OF JUGULAR VENOUS OXIMETRY DURING CAROTID ENDARTERECTOMY

AJ Davidson, AD Mendelow, IR Chambers. Newcastle General Hospital, Newcastleupon-Tyne, UK

Objective-To measure jugular bulb oxygen saturation during carotid endarterectomy.

Design-Prospective observational study. This was performed by means of a $40 \mathrm{~cm} 4$ FG Opticath fibreoptic catheter connected to an Oximetric 3 computer and recorded continuously on a paper hard copy and a Psion computer. The fibreoptic catheter was positioned by the surgeon under direct vision via a facial vein tributary into the jugular bulb on the operative side and removed at the end of the procedure. Other monitoring included ECG, invasive blood pressure, central venous pressure, pulse oximetry, and end tidal capnography.

Patients-Twenty patients undergoing carotid endarterectomy under either local or general anaesthesia depending on the preference of the patient and surgeon.

Outcome-Assessed correlation of peroperative monitoring with neurological outcome.

Results-The system provided a reliable, continuous, real time monitor of jugular bulb saturation during surgery. Observation of changes in jugular bulb saturation and correlation with neurological deficits in those patients under local anaesthesia alone greatly aided in blood pressure manipulation and in the decision as to the need to insert temporary bypass shunts. Typical patterns seen included falls in jugular saturation associated with hypotension and hence inadequate cerebral perfusion and profound falls in saturation on carotid cross clamping relieved by insertion of temporary shunts. Equally useful were stable readings obtained during general anaesthesia or cross clamping, thus avoiding the potentially deleterious side effects that might occur with shunt insertion, fluid loading, or inotropic drug treatment given in an attempt to raise blood pressure.

Conclusions-Jugular venous oximetry is a valuable monitor to aid in the peroperative care of patients undergoing carotid endarterectomy.

[SBNS]
EFFECT OF ANGIOGRAPHY, ANAESTHESIA, AND OPERATION ON INTRACRANIAL PRESSURE IN PATIENTS WITH ANEURYSMAL

SUBARACHNOID HAEMORRHAGE

SS Praharaj, IR Chambers, A Clark, PJ Crawford, A Jenkins, NV Todd, RP Sengupta, A Gholkar, AD Mendelow. University of Newcastle-upon-Tyne and Regional Medical Physics Department, Newcastle-upon-Tyne, UK

Design-A total of 18 patients with suspected aneurysmal subarachnoid haemorrhage (SAH) had intracranial pressure (ICP) monitoring measured during transfemoral digital subtraction angiography under local anaesthesia. Five of these also had their ICP monitored during anaesthesia and operation. ICP was measured with a Camino pressure transducer. Simultaneously, blood pressure was measured either with a cuff or arterial line. Results-Angiography raised the ICP in all patients. Preangiographic ICP was 11.59 (1.54) $\mathrm{mm} \mathrm{Hg}$, whereas perangiographic peak ICP was $23.61 \quad(4.68) \mathrm{mm} \mathrm{Hg}$. Intubation during anaesthesia was the single most important variable affecting ICP, which rose from between 3 and $87 \mathrm{~mm} \mathrm{Hg}$ (average rise $24.5(15.9) \mathrm{mm} \mathrm{Hg}$ ). A corresponding rise in MAP, however, ensured a relatively stable CPP.

Conclusion-These findings suggest that the greatest haemodynamic disturbance to patients with subarachnoid haemorrhage occurs during intubation. This strengthens the case for performing angiography under local anaesthesia.

[SBNS]

EXPERIENCES WITH AN ARTIFICIAL CERVICAL JOINT

BH Cummins. Frenchay Hospital, Bristol, UK

Most surgical procedures on the cervical spine include fusion by bone, metal, or both. Over the years such fusion at one or more spaces may be associated with osteophytic degeneration at the adjacent levels, causing radiculopathy or myelopathy.

In 10 "last ditch" spaces of such disorder accompanying multiple levels of congenital or surgical fusion, an artificial joint designed by the author and made by the engineering department of the hospital has been inserted to provide some degree of flexibility at that level.

The joint is of stainless steel in two pieces, the upper with a downward facing dome slightly smaller in radius than the shallower saucer of the upper face of the lower piece. This allows rotation, limited flexion, and extension and glide. Locking screws maintain the joint in position.

Technically this has proved satisfactory and nine of the 10 joints have provided resolution of symptoms in these difficult cases. [SBNS]

BIOCOMPATIBLE OSTEOCONDUCTIVE POLYMER $V$ ILIAC GRAFT IN ANTERIOR CERVICAL DISCECTOMY: A PROSPECTIVE COMPARATIVE STUDY ON 110 PATIENTS OPERATED ON FOR CERVICAL DISC DISEASE AA Madawi, M Powell, HA Crockard. The National Hospital for Neurology and Neurosurgery, London, UK

Donor site morbidity is a significant problem in anterior cervical fusion. A biocompatible 
osteoconductive polymer (BOP) has been used in many centres to circumvent these problems. A prospective study was performed to evaluate its use and long term effectiveness.

Materials and methods-One hundred and ten patients, 50 for iliac graft (IG) and 60 for BOP were recruited into this study. 72 patients were radiculopathic, 20 myelopathic, and 18 were radiculomyelopathic. The mean duration of symptoms was 20.3 months. The Smith Robinson technique was used in 70, and the Cloward technique in 40 patients; 80 patients had one level, 30 had two level surgery. Patients were followed up routinely at three to six month intervals (range 3-24, mean 11 months) at which time clinical and radiological assessment were made, including CT and MRI.

Results-The mean hospital stay was 5.9 days for those with IG, and $5 \cdot 1$ days for BOP. Complications were recorded as two neck haematomas required evacuation, one iliac wound haematoma was managed conservatively, two graft non-unions with kyphus (IG) required revision and plating, two complete graft extrusions (one IG, one BOP) required revision. Partial graft extrusion occurred in $18 \mathrm{IG}$ (2-5 mm, mean 3 $\mathrm{mm}$ ) and seven BOP (2-4 mm, mean $2 \cdot 6$ $\mathrm{mm})$. Kyphus was found in 13 IG (3-30, mean 12.3 degrees) and in four BOP (mean $3-15,10 \cdot 3$ degrees). The BOP sank into the adjacent endplates and the space collapsed after Smith Robinson procedures. Also sclerosis was found around BOP within one to two months, but even by 18 months there was no incorporation or degradation. Osseous union was seen to begin within one to two months and had finished by one year in 48 cases after IG.

Conclusion-BOP can act as a good spacer after anterior cervical fusion, with evidence of incorporation or degradation through the period of follow up.

[SBNS]

EXTENDED ANTERIOR CERVICAL DISCECTOMY WITHOUT FUSION: A SIMPLE AND SUFFICIENT OPERATION FOR MOST CASES OF CERVICAL DEGENERATIVE DISEASE

RS Maurice-Williams, N Dorward. Royal Free Hospital and School of Medicine, London, UK

Of 291 operations performed for cervical degenerative disease causing cord or root involvement over a 12 year period 187 have been treated by extended anterior discectomy without fusion, removing bone on either side of the posterior disc space so as to give a wide exposure of the anterior spinal and root dura. This technique has been used for $73 \%$ of the cases operated on in the past four years. Nine patients $(4 \cdot 8 \%)$ required additional posterior decompression for coexisting spinal or root canal stenosis. By the first postoperative follow up at two to four months $94.5 \%$ of patients showed clear neurological or functional improvement, $3 \%$ were unchanged, $1 \%$ were worse, and $1.5 \%$ had died (the deaths were in elderly patients with severe myelopathy and intercurrent disease). Minor treatable complications occurred in $3.2 \%$. Only two patients (1\%) complained of postoperative neck pain. Patients were mobilised immediately after surgery without a collar and most left hospital within one to four days. A single level decompression was sufficient in $92 \%$ of patients and only one patient required more than two levels to be decompressed. In $79 \%$ of cases soft disc protrusions contributed to the compression whereas in $21 \%$ osteophytes alone caused the compression. We believe that this simple technique is a sufficient surgical treatment for most cases of cervical degenerative disease. It does not require a fusion and avoids the specific problems and complications associated with Cloward type operations. A long term follow up study of these patients is presently being carried out and to date no late problems have become apparent.

[SBNS]

A RANDOMISED CONTROLLED TRIAL COMPARING AUTOMATED PERCUTANEOUS LUMBAR DISCECTOMY AND LUMBAR MICRODISCECTOMY

G Findlay, S Chatteriee, P Foy. Walton Centre for Neurology and Neurosurgery, Liverpool, UK

Much interest has been created by the advent of automated percutaneous lumbar discectomy (APLD) in the management of contained lumbar disc herniation. Several papers have reported encouraging results but to date attempts to perform controlled studies of APLD have been hampered by numbers too small to be statistically significant. We designed a randomised study with a separate blind assessor to compare the results of APLD with conventional lumbar microdiscectomy. It was planned to recruit 180 patients to the study and to complete a two year follow up in all cases. During the study it became apparent to the non-blind participants that the results of APLD were much worse than surgery and it was decided to analyse the results at that stage.

This produced 70 patients who had small contained disc herniation proved by MRI (all other types were excluded from the study). In the APLD group only eight of $30(26 \cdot 7 \%)$ achieved excellent or good results, whereas the corresponding figure for the microdiscectomy group was 32 of $40(80 \%)$. Moreover for patients in the APLD group who had unsatisfactory results and opted for subsequent microdiscectomy (20 of 22 patients), the success rate was only 13 of 20 ( $65 \%)$. Thus the eventual success rate of those treated by APLD alone or APLD and microdiscectomy was 21 of 30 (70\%).

A recent controlled study comparing APLD to chemonucleolysis also showed poor results for APLD. Our study shows that in the chosen group of patients APLD is ineffective. Our success rate for microsurgery for all types of disc herniations was found to be $91 \%$ and better than the $80 \%$ we found for the selected group in our study.

It is considered that a trial is needed to compare the results of APLD with conservative treatment and that a third control group of patients who had neither surgery nor APLD would have been valuable in this study. [SBNS]

SPINAL MENINGIOMAS: A 20 YEAR REVIEW AT King, B Doshi, RW Gullan, MM Sharr, JR Bartlett. Brook General Hospital, London, UK

This is a retrospective study of 78 patients with spinal meningiomas operated on over 20 years at the Brook Neurosurgical Unit. The age range was 22-91 (mean 61.5 ) years, with 12 men (15\%) and 66 women $(85 \%)$, followed up for a mean of 10.5 years. The clinical history was of less than one year in 55 patients and less than six months in 26 patients. There was poor correlation between presenting complaint and relation to the spinal cord: 15 lay anteriorly, 15 anterolaterally, 23 laterally, 17 posterolaterally, and eight posteriorly. Plain radiology was normal in the entire intradural group (74 patients) with only one example of tumour calcification. Three out of the four extradural group showed abnormalities on plain radiology. Two tumours were purely extradural and a further two both intradural and extradural. The dural attachment was excised in 20 cases. Full recovery of function was achieved in 57 patients (73\%), and a further $17(22 \%)$ were improved to independent mobility. There was one recurrence, at 14 years after operation. By contrast with previous series, histology showed no striking predominance of psammomatous meningiomas. [SBNS]

TRANSDURAL MICRONEUROSURGICAL EXCISION OF PROLAPSED DORSAL DISCS JM Rice Edwards, D Peterson. Charing Cross Hospital, London, UK

A tenet of neurosurgical practice is that a laminectomy should not be done for the removal of dorsal discs. This belief is based on historical evidence of operations performed with rongeurs and of impossible attempts to remove anterior lesions extradurally.

An operation is described which involves careful removal of laminae with a drill and a transdural microapproach to the dorsal disc.

After removing the lamina the spinal cord is not usually displaced against the dorsal dura and a very adequate view of the anterior disc can be obtained laterally without significant retraction of the spinal cord. It has been possible to completely remove the hard disc prolapse in the 10 cases where this approach has been used.

The technique has the following advantages: the approach is familiar to neurosurgeons whereas the anterolateral and transthoracic approaches can be difficult unless practised often, the spinal cord can be inspected for adhesions to the dura (which occurred in two cases with associated arachnoiditis), it is safe providing that the disc protrusion is not of an extreme size. This can be judged from MRI.

[SBNS]

\section{Poster Presentations}

ASYMPTOMATIC CNS ABNORMALITIES IN BEHÇET'S DISEASE: A MAGNETIC RESONANCE STUDY

F Ahmed, JM Bamford, KS Blanshard, BA Noble. St James's University Hospital, and the General Infirmary, Leeds, UK

Involvement of the CNS occurs in up to one third of patients with Behçet's disease, designated as neuro-Behçet's disease. Clinical features are either due to cerebral venous thrombosis or parenchymal pathology. 
Prognosis of neuro-Behçet's disease is poor and early intervention may modify the course of the disease. Early diagnosis is, therefore, desired before the development of disabling neurological sequelae. Asymptomatic abnormalities on MRI have been reported but their prevalence is unknown. The results of the initial assessment of a cohort of patients with MRI and angiogram who will be followed prospectively are reported.

Eighteen patients fulfilling the International Study Group (ISG) criteria for the diagnosis were assessed. None had symptoms and signs on routine examination to suggest current or previous involvement of the nervous system. Their disease activity was assessed according to ISG recommendations.

Magnetic resonance angiograms were normal in all cases. Thirteen patients had normal MRI. Other scans showed high signal intensity in T2 weighted images, either as single lesions $>10 \mathrm{~mm}$ or multiple lesions $(5-10 \mathrm{~mm})$ in the cortex and periventricular region.

It is concluded that asymptomatic MR abnormalities in patients with Behçet's disease are uncommon and are not related to duration of the disease or its activity in other systems. Whether these abnormalities predict future neuro-Behçet's disease is uncertain.

[ABN]

A SURVEY OF THE USE OF LAMOTRIGINE AND VIGABATRIN IN CLINICAL PRACTICE

D Chadwick, G Schapel. University of Liverpool, Liverpool, UK

A survey was undertaken between September 1993 and February 1994 that identified 356 patients who had been prescribed either vigabatrin or lamotrigine since the licensing of these compounds from a comprehensive database of just over 2200 patients with epilepsy attending the Mersey Regional Epilepsy Clinic since 1989. The population had a chronic refractory epilepsy; $90 \%$ were having more than one seizure per week and two thirds were receiving one drug.

Two hundred and twenty three patients were exposed to lamotrigine for up to 56 months and 217 patients to vigabatrin for up to 72 months. The median maximum dose of lamotrigine achieved was $400 \mathrm{mg}$ per day and that for vigabatrin was $2 \mathrm{~g}$ per day. Kaplan-Meier survival curves were plotted for time to withdrawal of the new drug. The probability of continuing on lamotrigine at 40 months was $57 \%$ compared with $43 \%$ for vigabatrin. The commonest adverse event causing withdrawal of lamotrigine was skin rash (5\% of patients exposed), whereas adverse psychiatric consequences were the commonest reason for withdrawal of vigabatrin ( $8 \%$ of cases). Ten per cent of patients exposed to lamotrigine became seizure free compared with $6 \%$ exposed to vigabatrin. Most of the patients becoming seizure free on lamotrigine were those with generalised epilepsies and there was little difference between the outcomes for the new drugs in partial epilepsies.

This survey indicates that there is little difference in the efficacy of these two novel drugs in the partial epilepsies. The side effect profile of the drugs seems radically different as does the range of activity, lamotrigine exhibiting a broad range of activity; and particular effectiveness in more resistant forms of idiopathic generalised epilepsy. [ABN]

MAGNETIC RESONANCE SPECTROSCOPY IN IDIOPATHIC PARKINSON'S DISEASE WITH MOTOR OSCILLATIONS

K Ray-Chaudhuri, G Lemmens, C Ellis, J Dawson, JD Parkes, S Williams, PN Leigh. King's College School of Medicine and Dentistry, London, UK

The mechanism of motor fluctuations in idiopathic Parkinson's disease (IPD) is not clear. The striatal neuronal and biochemical alterations that have been reported in Parkinson's disease are based mainly on postmortem, not in vivo studies. MRS was used with regions of interest in the putamen and cerebellum to investigate eight patients with probable idiopathic Parkinson's disease (mean age 54 (9) years) on levodopa treatment with motor fluctuations. Results were compared with results with six age matched healthy controls (mean age 52 (10) years). Spectra were collected using a STEAM sequence at an echo time of $136 \mathrm{~ms}$. Scans were obtained in the "off" rather than "on" condition.

There was a significant reduction in putamen NAA/creatine ratios in patients with idiopathic Parkinson's disease (mean 1.104 (SD 0.17)) compared with controls (mean 1.62 (SD 0.21), $\mathrm{P}<0.001$ ). NAA/choline ratios were also lower in the putamen of patients with idiopathic Parkinson's disease $(1.106$ (SD 0.16)) compared with controls (1.52 (SD 0.36), $P<0.03$ ). There were no significant differences between values for these ratios in the cerebellum in idiopathic Parkinson's disease compared with controls. These findings suggest the presence of axonal and/or neuronal damage in the putamen in late idiopathic Parkinson's disease. This may be related either to the disease itself or to the effects of long term levodopa treatment.

[ABN]

A COMPREHENSIVE ELECTROPHYSIOLOGICAL EVALUATION OF PHRENIC NERVE INJURY RELATED TO OPEN HEART SURGERY

E Chroni, RL Patel, N Taub, GE Venn, RS Howard, CP Panayiotopoulos. St Thomas' Hospital, London, UK

Phrenic nerve damage is a widely recognised complication of open heart surgery. A prospective electrophysiological study of phrenic nerve function was conducted in 59 patients undergoing cardiopulmonary bypass. The right and left phrenic nerves were stimulated percutaneously at the neck and the diaphragmatic responses were recorded with surface electrodes placed over the 8th intercostal space. The latency, amplitude, duration, and area of the evoked responses were measured before and after the operation. Postoperatively no responses were elicited in two patients bilaterally, in five from the left, and in two from the right phrenic nerve. Comparison of the postoperative with the preoperative group values in the remaining patients showed that the amplitude and area of the left phrenic nerve were lower in the postoperative study, indicating that some of the nerve fibres were not conducting. There were no statistically significant differences between pre and postoperative values of latency or duration on the left or any of the parameters on the right. Follow up studies showed that in eight of nine nerves with unobtainable responses postoperatively, the conduction returned in four to seven weeks. The findings suggested that the amplitude and area of the diaphragmatic response are more sensitive than latency in detecting phrenic nerve paresis associated with open heart surgery. [ABN]

SPONTANEOUS INTRACRANIAL HYPOTENSION FROM A CSF LEAK IN A PATIENT WITH MARFAN'S SYNDROME

RJ Davenport, SJS Chataway, CP Warlow. University of Edinburgh, Western General Hospital, Edinburgh, UK

A 21 year old girl with known Marfan's syndrome first presented in 1992 with a short history of severe postural headaches reminiscent of a postlumbar puncture (LP) headache. Other than the features of her Marfan's syndrome the examination was normal. A CT brain scan was normal but at LP the opening pressure was unrecordable. She recovered spontaneously but two years later presented with an identical headache of such severity that she required admission to hospital.

Radioisotope cisternography showed an abnormal accumulation of isotope at the $T 1$ level suggestive of a CSF leak; CT myelography confirmed this leak and multiple arachnoid diverticulae around the lumbrosacral nerve roots were also identified.

A saline epidural infusion led to an immediate and dramatic improvement in her symptoms. This improvement has been maintained after two thoracic epidural autologous blood patches and a subsequent radioisotope cisternogram has not shown any leak.

It is proposed that the patient's headache was caused by a low CSF pressure secondary to a CSF leak from the spinal subarachnoid space, after rupture of one of the many demonstrated arachnoid diverticulae, which are associated with Marfan's syndrome. The rupture may have been either spontaneous or following minor unrecognised trauma. Treatment with site specific epidural blood patching has proved remarkably successful. [ABN]

AN INVESTIGATION OF DIFFUSE AXONAL INJURY OCCURRING AFTER CLOSED HEAD TRAUMA

CA Davie, R Greenwood, IF Moseley, WI McDonald, $\mathrm{DH}$ Miller. Institute of Neurology, London, UK

Pathological studies in patients with severe head injury often show changes of diffuse axonal shearing. The abnormalities detected by MRI are often insufficient to explain the deficits of memory or changes in personality that can occur. Proton magnetic resonance spectroscopy (MRS) may be useful in assessing the presence of axonal loss or dysfunction by observing changes in N-acetylaspartate (NAA)-a neuronal marker. MRI and MRS have been carried 
out in six patients with a history of severe head trauma and in eight healthy controls.

MR images of the brain were collected followed by long echo proton MRS from a localised volume of normal appearing white matter (NAWM) in the left frontal lobe. In five patients there was mild cerebral atrophy with ventricular dilatation and in one patient, more severe cerebral atrophy. There was a significant reduction in the concentration of NAA (median $8.22 \mathrm{mM}$, range 6.5-8.8 $\mathrm{mM}$ ) from frontal NAWM in the patient group compared with healthy controls (median 10.44 $\mathrm{mM}$, range 8.76-10.81 $\mathrm{mM}, \mathrm{P}<0.006)$. There was no significant difference in the concentrations of creatine and choline containing compounds between the two groups. Proton MRS may be useful in measuring the extent and degree of axonal loss and/or dysfunction occurring after closed head injury.

$[\mathrm{ABN}]$

AUTOSOMAL DOMINANT DESMINOPATHY WITH A DISTAL MYOPATHY AND HEART BLOCK

DJ Dick, JR Anderson. Norfolk and Norwich Hospital, Norwich, and Addenbrooke's Hospital, Cambridge, UK

Three members of one family over two generations were found to have heart block and a distal myopathy. Neurological examination of the index case showed a distal pattern of muscle weakness with preserved reflexes and normal sensation. Electromyography, ECG, serum creatine kinase, and an ischaemic lactic test were normal. A muscle biopsy showed selective type 2 atrophy and mainly subsarcolemmal eosinophilic plaques of cytoplasm. Immunohistochemical staining showed that these deposits stained positively for desmin and to a lesser extent for ubiquitin, actin, and glycogen. Electromicroscopy of the deposits showed the presence of glycogen granules and electron dense granular material, which was often closely associated with a smeared $\mathrm{Z}$ band.

These are the muscle biopsy features of a desminopathy, which in this family is inherited as an autosomal dominant trait. This is a rare disorder in which there is accumulation of desmin in skeletal muscle and presumably there are similar abnormalities to be found in cardiac muscle or the conducting system. Desmin is one of the intermediate neurofilaments and is a structural component of the cytoskeleton of mature muscle. It anchors myofibrils in the transverse plane and to the sarcolemma. The mechanism by which desmin accumulates in this condition is not clear.

Previously reported cases have been mainly sporadic and if cardiac involvement occurred, it took the form of cardiomyopathy.

[ABN]

A METHOD OF CHARACTERISING CEREBRAL ATROPHY

M Doran, N Roberts, RHT Edwards. University of Liverpool, Liverpool, UK

The aim was to evaluate the patterns and morphological characteristics of cerebral atrophy using volumetric MRI.

Volumetric MRI was obtained from patients with focal aphasic syndromes. The images were analysed with stereological grids to determine the cross sectional area (A) and cortical boundary length (B) on each image. Profile plots of the cross sectional areas (A) and the complexity parameter $B / \int A$ of individual lobes of each hemisphere were obtained.

The data for patients with focal aphasic syndromes show distinct anterior or posterior patterns of morphological change in the temporal lobes. Interval scans show that significant quantitative changes can on occasion be precisely determined within a period of one year. The pattern of the changes has been related to the evolving pattern of neuropsychological deficit.

It is concluded that stereology represents a rapid and efficient method of determining morphological data to characterise the pattern of atrophic change in cortical disease. [ABN]

INCREASED SOLUBLE VCAM-1 CONCENTRATIONS IN CSF OF PATIENTS WITH MULTIPLE SCLEROSIS

AG Droogan, SA McMillan, JP Douglas, SA Hawkins. Royal Victoria Hospital, Belfast and Belfast City Hospital, Belfast, UK

Factors determining the composition and temporal evolution of the inflammatory infiltrate in multiple sclerosis are unknown, but the profile of adhesion molecule expression at the site of the lesion may play a part. Activated cerebral vascular endothelial cells express leucocyte, vascular cell, and intracellular adhesion molecules (E-selectin, VCAM-1, and ICAM-1), which facilitate leucocyte adhesion to endothelium and migration into inflammatory lesions. Serum and CSF concentrations of soluble (s) Eselectin, sVCAM-1, sICAM-1 were determined by enzyme linked immunosorbent assay in 51 patients with clinically definite multiple sclerosis, 28 patients with inflammatory neurological disease (IND), and 39 patients with non-inflammatory neurological disease (NIND). Concentrations of sVCAM-1 in CSF were significantly increased in multiple sclerosis (mean (SD), $18.3(9.9) \mathrm{ng} / \mathrm{ml})$ compared with IND $(11.3$ $(7 \cdot 3) \mathrm{ng} / \mathrm{ml}, \mathrm{P}=0.001)$ and NIND $(10.6$ $(5 \cdot 3) \mathrm{ng} / \mathrm{ml}, \mathrm{P}=0.0001)$. Serum and CSF concentrations of SICAM-1 were normal in each group. Serum sE-selectin was decreased in multiple sclerosis compared with NIND (45.5 (23.9) ng/ml v 55.0 (19.9) $\mathrm{ng} / \mathrm{ml}, \mathbf{P}=0.03$ ). In multiple sclerosis, high CSF concentrations of SVCAM-1 and sICAM-1 correlated with the presence of CSF oligoclonal bands $(P=0.004$ and $P=$ 0.001 respectively). Measurement of soluble VCAM-1 in CSF therefore seems to provide a marker of disease activity in multiple sclerosis. [ABN]

PERIPHERAL NERVE BLOCKADE WITH PHENOL IN SPASTICITY: A MYOMETRIC AND FUNCTIONAL ASSESSMENT

S Duckworth, N Jordan. Hunters Moor Regional Rehabilitation Centre, Newcastleupon-Tyne, UK

Spasticity remains a significant cause of neurological disability. Oral pharmacological treatment is associated with unwanted side effects. Selective tone management is of value. Peripheral nerve phenol injections have been shown to produce tone changes. This effect may be of functional value in the management of spasticity. A myometric paradigm was employed alongside standard measures of disability to assess the effect of local phenol injection into different sites in 23 patients with spasticity. The amount of force required to move the selected joint through a predetermined range was made before and after injection and at one month after injection. Results showed significant tone reduction in ankle plantarflexion $(n=$ $14, P<0.001$ ), knee flexion $(n=14, P<$ $0.01)$, leg adduction $(n=9, P<0.01)$, elbow flexion ( $n=9, P<0.05)$, and finger flexion ( $n=2, P<0.001)$. The effect was maintained at one month after injection at the ankle $(\mathrm{n}=7, \mathrm{P}<0.001)$, knee $(n=14, P<0.05)$, leg adduction $(n=9, P$ $<0.01)$, and fingers $(n=2, P<0.05)$ but not at the elbow ( $n=7, P=0.51)$. Overall activities of daily living scores improved significantly after injection $(n=23, P<0.01)$. This study confirms the usefulness of peripheral nerve blockade with phenol in the management of spasticity using a myometric paradigm and standard measures of overall function.

[ABN]

INTEROBSERVER VARIATION IN CLASSIFYING MULTIPLE SCLEROSIS

HL Ford, MH Johnson, AS Rigby. St James's University Hospital, Leeds, UK

With the advent of new treatments for multiple sclerosis, clinicians must be able to use diagnostic criteria reliably and to define the course of multiple sclerosis. The aim was to determine if the Poser diagnostic criteria could be applied consistently in practice and the course of multiple sclerosis defined.

The case records of 85 consecutive outpatients with multiple sclerosis were retrospectively analysed by two independent observers. The cases were classified: clinically definite multiple sclerosis, laboratory supported definite multiple sclerosis, clinically probable multiple sclerosis, laboratory supported probable multiple sclerosis, suspected multiple sclerosis, and unable to classify; the course was defined as early relapsing-remitting, benign, secondary progressive, primary progressive, and unable to classify.

The statistical agreement between the two observers was measured by calculating the $\kappa$ statistic. There was substantial agreement in classifying the cases $(\kappa=0.65,95 \% \mathrm{CI}=$ $0.52-0.78)$. The main disagreement lay in defining attacks of multiple sclerosis $(\kappa=$ $0.30,95 \% \mathrm{CI}=0.03-0 \cdot 57)$. There was moderate agreement for determining the course of multiple sclerosis $(\kappa=0.57,95 \%$ $\mathrm{CI}=0.43-0.71)$. The observers differed in their definition of primary progressive and secondary progressive cases. This may be due to the poor documentation of relapses and remissions early in the disease course.

The efficacy of new treatments is being judged on relapse rate. Consensus definition of an attack of multiple sclerosis is therefore essential. Each attack should be well documented, as should subsequent clinical improvement. The definition must be rigorously adhered to to allow consistent application of diagnostic criteria in practice. [ABN] 
ANTI-PURKINJE CELL CYTOPLASMIC ANTIBODIES. ARE THEY NON-SPECIFIC MARKERS OF CEREBELIAR CELL DAMAGE? A Gibson, M Hadjivassiliou, A Milfordand Northern General Hospitals, Sheffield, UK

Anti-Purkinje cell antibodies that recognise discrete antigenic components within Purkinje cell cytoplasm have been designated "anti-Yo" and shown by some authors to be strongly associated with paraneoplastic cerebellar degeneration. The association is not universally accepted and may merely reflect Purkinje cell damage.

We have used an immunofluorescent method, with monkey cerebellar slices as substrate, to detect the presence of a Purkinje cell cytoplasmic antibody in patients with and without cerebellar signs as well as a group of age and sex matched healthy controls.

A total of 60 ataxic patients with mean age 49 years and a male to female ratio of unity were compared with 28 neurological controls without cerebellar signs and 50 healthy controls with mean age 50 years and the same male to female ratio. The proportions of cytoplasmic antibody positives in the three groups were $40 / 60,1 / 28$, and $4 / 50$ respectively. Using analysis of proportions shows that these differences are significant at the 0.001 level or less.

It remains to be seen if the antibody described here is the same as that described elsewhere but further characterisation of the antigenic determinant with western blot analysis should resolve this issue.

[ABN]

EVALUATION OF A COMPUTER ASSISTED QUANTIFICATION OF MULTIPLE SCLEROSIS LESIONS IN CRANIAL MRI

J Grimaud, M Lai, JW Thorpe, P Adeleine, D Plummer, G Barker, PS Tofts, WI McDonald, DH Miller. Institute of Neurology, London, UK

Several computer assisted techniques for measuring multiple sclerosis lesion volume on MRI have been developed to provide an objective, quantitative, and sensitive means for monitoring disease activity, particularly in the context of treatment trials. We have evaluated three techniques: manual tracing interferon trial), automated lesion contouring (local lesion based threshold) and intensity based thresholding for the whole brain. Contiguous $5 \mathrm{~mm}$ thick axial proton density images of the brain were obtained on a $1.5 \mathrm{~T}$ MR imager in eight patients with definite multiple sclerosis. Analysis of the scans were performed twice, independently by three operators, using the three different techniques.

The table shows the results. The autoWard, GAB Davies-Jones. Royal Hallamshire (similar to that of the North American $\beta$

mated lesion contouring technique was the most reproducible and should therefore be considered for use in treatment trials. Further studies are needed to assess sensitivity to changes in lesion load over time. [ABN]

LNK, A NEW CLASS OF PROTEIN KINASE: HIGH EXPRESSION LEVELS IN GLIOMAS AND DURING HUMAN NERVOUS SYSTEM DEVELOPMENT

NJ Gutowski, R Ludwig, C Proschel, M-J

Blouin, $M$ Noble. Ludwig Institute for

Cancer Research, London, UK

Protein kinases that include growth factor receptors are central in mediating division and differentiation in the nervous system and may also be important as cell lineage markers.

From the cDNA library of a human glioblastoma multi forme cell line of the oligodendrocyte type 2 astrocyte $(0-2 A)$ lineage a new protein kinase LNK was cloned. LNK represents a new class of protein kinase. Although it contains all conserved motifs in the kinase domain it has low overall amino acid homology to other kinases in this domain. It also has two LIM domains in the amino terminal region possibly indicating a transcriptional role. By northern analysis on total RNA, the LNK $3.3 \mathrm{~kb}$ band has been found to be upregulated in many glioblastoma primary cell populations. In the mouse the highest expression of murine LNK is found in the nervous system. Expression of LNK has been found in the developing human nervous system by in situ hybridisation.

These findings may be consistent with LNK having a regulatory role in human CNS development, in gliomas, and also as a cell lineage marker.

[ABN]

UPTAKE OF SERVICES FOR EPILEPSY AND THE COSTS OF CARE

A Jacoby, G Baker, D Chadwick. Universities of Newcastle-upon-Tyne and Liverpool, UK

Epilepsy is a common neurological condition and it is estimated that in the United Kingdom there are presently around $\mathbf{3 0 0 0 0 0}$ people with active epilepsy. The resource implications of caring for these patients are likely, therefore, to be significant. A recent community study in one health region in the United Kingdom has examined the uptake of medical services among people with epilepsy and calculated the direct and indirect costs of their care. Patients included in the study were identified through the medical records of a random sample of general practitioners in the region. The pattern of care was very different for adults and children, reflecting in part the natural history of epilepsy: thus $86 \%$

\begin{tabular}{|c|c|c|c|c|c|c|}
\hline \multirow[b]{2}{*}{ Techniques } & \multicolumn{3}{|c|}{ Intraobserver agreement } & \multicolumn{3}{|c|}{ Interobserver agreement } \\
\hline & Min & $\operatorname{Max}$ & Mean $(S D)$ & Min & $\operatorname{Max}$ & Mean $(S D)$ \\
\hline $\begin{array}{l}\text { Manual } \\
\text { Contouring } \\
\text { Thresholding }\end{array}$ & $\begin{array}{l}0 \cdot 4 \\
0 \cdot 1 \\
0 \cdot 2\end{array}$ & $\begin{array}{l}18 \cdot 5 \\
7 \cdot 7 \\
22\end{array}$ & $\begin{array}{l}9 \cdot 0(5 \cdot 2) \\
2 \cdot 48(2 \cdot 1) \\
7 \cdot 5(6 \cdot 9)\end{array}$ & $\begin{array}{l}4 \cdot 9 \\
1 \cdot 8 \\
2 \cdot 8\end{array}$ & $\begin{array}{r}21 \cdot 7 \\
6 \cdot 6 \\
19 \cdot 2\end{array}$ & $\begin{array}{r}11 \cdot 0(5 \cdot 8) \\
4 \cdot 5(1 \cdot 6) \\
11 \cdot 4(4 \cdot 9)\end{array}$ \\
\hline
\end{tabular}

Coefficients of variation of the measurement techniques $(0 \cdot 0=$ perfect reproducibility). of children had a hospital outpatient attendance in the past year compared with only $31 \%$ of adults; children were also significantly more likely to have had diagnostic investigations.

The largest single cost to the health service was the drug cost, representing around $40 \%$ of the total; inpatient costs also accounted for a sizeable proportion of costs. Uptake of medical services was significantly higher among patients with frequent seizures-for example, mean number of inpatient admissions was 1.6 among adults with frequent seizures, compared with 0.01 among those seizure free. People with frequent seizures also had a much higher uptake of state benefits. Improvements in the management of epilepsy may improve seizure control, which is the key to reducing the direct and indirect costs of this condition.

[ABN]

WEEKLY $V$ MONTHLY BRAIN MRI FOR DETECTION OF DISEASE ACTIVITY IN MULTIPLE SCLEROSIS

HM Lai, T Hodgson, DG MacManus, S Webb, WI McDonald, DH Miller. Institute of Neurology, London, UK

In therapeutic trials, MRI at monthly intervals is often used to evaluate efficacy. At such an interval, $80 \%$ of new lesions on T2 weighted images enhance, and conversely, about $50 \%$ of new gadolinium enhancing lesions are not associated with clear changes on the T2 weighted image. Weekly T2 and gadolinium enhanced brain MRI were performed for three months in three patients with clinically active relapsing progressive multiple sclerosis.

On weekly MRI 38 new enhancing lesions were seen. On monthly scans there were 33 new enhancing lesions but only 13 new T2 lesions. Twenty five lesions were followed up from when they first enhanced until they had stopped enhancing. Of these 11 (44\%) enhanced for less than four weeks (one to three weekly scans). All new T2 lesions showed initial enhancement.

Monthly gadolinium enhanced MRI is only slightly less sensitive than weekly scanning in detecting disease activity, and is still the preferred frequency for monitoring treatment as it is easier to perform. It seems from weekly studies that virtually all new $T 2$ lesions undergo an initial phase of enhancement - as this may occasionally be as short as one to two weeks, it is sometimes missed on monthly studies.

[ABN]

$X$ LINKED DOMINANT HEREDITARY MOTOR AND SENSORY NEUROPATHY WITH CX32 MUTATION

BRF Lecky, PK Thomas, S Malcolm. Walton Centre for Neurology and Neurosurgery, Liverpool, Royal Free Hospital School of Medicine, and Institute of Child Health, London, UK

Three generations of a family are described with hereditary motor and sensory neuropathy (HMSN). Inheritance is consistent with $\mathrm{X}$ linked dominant transmission, which is also suggested by the more severe clinical involvement of affected males. The onset of symptoms is in early adolescence with distal 
wasting and weakness. A prominent symptom, not characteristic of HMSN types I or II, is of painful cramping of the extremities both on exercising affected muscles and spontaneously at night. Disability in affected females is not severe whereas affected males have considerable difficulty with both manual function and gait.

Nerve conduction studies show reduced or absent sensory action potentials with mild to moderate slowing of motor conduction velocities, although not to the extent usually found in HMSN type I.

The gene for the gap junction protein connexin 32 is located on the long arm of the $X$ chromosome. This group of proteins is known to connect the cytoplasmic compartments of cells. Their precise role is not known in neural tissue but $\mathrm{C} \times 32$ occurs in mammalian peripheral nerve at the nodes of Ranvier and in Schmidt-Lanterman incisures. Several different point mutations of $\mathrm{Cx} 32$ have been described. The present family shows a methionine for valine substitution at position 139 .

[ABN]

NEUROPHYSIOLOGICAL EXAMINATION OF RESPIRATORY MUSCLE FUNCTION IN MYOTONIC DISORDERS

VP Misra, RS Howard, BD Youl. National Hospital for Neurology and Neurosurgery, London, UK

Ventilatory failure in myotonic dystrophy is associated with weakness of the respiratory and bulbar muscles and a defect in central control. Previous reports have suggested the presence of myotonia in the primary and accessory muscles of respiration but this has not been studied in detail. Four patients with myotonia (three with myotonia dystrophica and one with myotonia congenita) were studied.

A concentric needle EMG examination was carried out by a standard technique. The obliquus externus abdominis, eighth intercostal, and diaphragm muscles yielded myotonic discharges in all patients. Additionally, all patients with myotonia dystrophica showed abnormally polyphasic motor units of short duration and low amplitude at all three loci.

The findings confirm that myotonia may affect respiratory muscles, including the diaphragm. In addition, myopathic changes are present in the diaphragmatic muscles of patients with myotonic dystrophy. [ABN]

TREATMENT OF PAINFUL FEET AND MOVING TOES WITH BOTULINUM TOXIN A

AP Moore, J Pilling. Walton Centre for Neurology and Neurosurgery, Liverpool and Norfolk and Norwich Hospital, Norwich, UK

Treatment of an underlying cause may help in the syndrome of painful feet and moving toes, but conventional treatment is often ineffective in idiopathic cases. Treatment with botulinum toxin A (BTx-A) has not been previously reported. We describe three women with painful feet and moving toes unresponsive to conventional treatment, and treated with local injections of BTx-A.
Patient 1, aged 47 had 18 months pain and wiggling of the right little toe. Injection of 150-250 MU Dysport three monthly into abductor digiti quinti and the fourth interosseous muscle has greatly improved involuntary movements and pain since 1989.

Patient 2 aged 50 had five years of wiggling movements of all toes and severe pain in the left foot and lower leg. Infiltration of 500 MU Dysport through the plantar fascia controlled movements for six months. Pain cleared for one month, and for a further year was reduced with an additional transcutaneous nerve stimulator. Further BTx-A injections controlled the movements but not the pain.

Patient 3, aged 37 had 18 years of pain and movements of all toes and both feet. Dysport (250 MU) infiltrated into each foot as for patient 2 suppressed the movements, but gave only two weeks of pain relief, and adjunctive measures were unsuccessful. Booster doses of $300 \mathrm{MU} /$ foot added no benefit.

More studies are needed, but BTx-A may control the movements and sometimes the pain in patients with this syndrome. [ABN]

HEADACHES IN THE ACCIDENT AND EMERGENCY DEPARTMENT: ARE WE OVERINVESTIGATING?

S Moreea, S Goodacre, $\mathrm{MH}$ Johnson. St James's University Hospital, Leeds, UK

A prospective study was conducted on all patients presenting to the accident and emergency department with a primary complaint of headache. They were followed up after three months to reach a final diagnosis.

In three months, there were 93 cases out of 21187 attendances $(0 \cdot 44 \%)$. Serious pathology was found in 10 patients: three subarachnoid haemorrhages $(3.2 \%)$, one intracerebral haemorrhage, three meningitis, and three cerebral neoplasms. 48 patients $(52 \%)$ were seen acutely by a neurologist, 31 being admitted. This included all cases of serious pathology except for one neoplasm. 39 patients $(42 \%)$ described a headache of sudden onset, the remaining having a headache of gradual onset. Of the first, six had serious pathology: the three subarachnoid haemorrhages $(7 \cdot 7 \%)$, the intracerebral haemorrhage, one neoplasm, and one meningitis. They were among the $18(46 \%)$ patients admitted from this group. Forty five patients $(48 \%)$ were referred by their general practitioner. Serious pathology was found in two of the 18 describing a sudden headache (one neoplasm and one subarachnoid haemorrhage) and two of the 27 with a headache of gradual onset (both neoplasms). In all, 30 $(32 \%)$ had a head CT, eight in the acute phase. There were seven other subarachnoid haemorrhages presenting differently during the study period.

The results highlight suboptimal use of resources. Is there a case for headache cards similar to head injury cards used in the accident and emergency department? [ABN]

DETECTION OF ENTEROVIRUS RNA IN THE CNS OF PATIENTS WITH PREVIOUS PARALYTIC POLIOMYELITIS

P Muir, F Nicholson, J Ajetunmobi, $\mathbf{M ~ L i}$, GT Spencer, RS Howard, JE Banatvala.
United Medical and Dental Schools and St Thomas' Hospital, London, UK

It has been suggested that the postpolio syndrome may be due to persistence or reactivation of poliovirus infection in the CNS. In view of this we decided to search for poliovirus and other enteroviruses in the CNS of patients with previous poliomyelitis to determine whether or not these viruses persist in the CNS in humans. Cerebrospinal fluid and peripheral blood was studied using a nested polymerase chain reaction for the presence of enterovirus RNA. Thirty patients have been studied. Enterovirus RNA was detected in CSF from one patient, in CSF and lymphocytes from a second patient, and in serum only from a third patient. By contrast enterovirus RNA was not detected in $30 \mathrm{CSF}$ samples from control patients without evidence of infectious disease. Four patients with previous poliomyelitis died from unrelated causes during the study. Fresh postmortem samples were available from three and enterovirus RNA was detected in spinal cord tissue from two patients. Nucleotide sequencing studies are underway to identify the enterovirus serotypes involved. It is unlikely that all patients in whom enterovirus was detected had acute infections. If this point is confirmed by further study, these results suggest that enteroviruses do persist in the CNS of patients with previous poliomyelitis, as recently demonstrated in patients with motor neuron disease. Further study is now required to understand the biological and clinical relevance of these findings. [ABN]

AN ASSESSMENT OF DIETARY AND SERUM $\omega-3$ POLYUNSATURATED FATTY ACIDS AND ANTIOXIDANTS IN NEWLY DIAGNOSED PATIENTS WITH MULTIPLE SCLEROSIS HES Mulholland, SA Hawkins, JJ Strain, IS Young, MBE Livingstone. Royal Victoria Hospital, Belfast, Queen's University, Belfast, and University of Ulster, Northern Ireland

There has been a longstanding interest in the relation of polyunsaturated fatty acids to the pathogenesis and treatment of multiple sclerosis. As soon as patients are given the diagnosis of multiple sclerosis most make changes to their eating habits. Many studies in the past, performed on patients with established multiple sclerosis, have shown low serum linoleic acid. There is little information on serum fatty acids in newly diagnosed patients. The lipid profile and antioxidant status in 30 newly diagnosed patients in the Neurology Department in Belfast were examined and compared with controls matched for age, sex, race, socioeconomic group, and smoking habits. Dietary intake was assessed using a seven day dietary history and a self administered food frequency questionnaire. Patients and controls ate similar diets. Serum and red cell membrane fatty acids were determined by gas liquid chromatography. Vitamins A, E, and carotenoids were measured by high performance liquid chromatography (HPLC). Lipid peroxidation was measured using the TBA reaction. No major differences in the blood concentrations of the variables examined were found.

[ABN] 
Hhal POLYMORPHISM IN THE CYP2D6 GENE IS NOT ASSOCIATED WITH PARKINSON'S DISEASE IN CAUCASIANS

DJ Nicholl, AC Williams, P Bennett, SL Ho, DB Ramsden. University of Birmingham, Birmingham, UK

A genetic association between mutant alleles of the cytochrome $P-450$ (CYP2D6) gene and Parkinson's disease has been reported. Polymorphisms in this gene, situated on chromosome 22, give rise to the autosomal recessive, poor debrisoquine metaboliser phenotype, and to a more than twofold increased risk of developing Parkinson's disease in Caucasian populations. Recently, a novel mutation, an Hhal polymorphism in CYP2D6 exon 6, was shown to confer a fivefold increased risk of Parkinson's disease in Japanese; we have studied this further in a Caucasian population where Parkinson's disease is more common.

DNA was analysed by the polymerase chain reaction (PCR) in 96 patients with sporadic Parkinson's disease and 60 controls, the products digested with Hhal restriction endonuclease, and the digest patterns studied after gel electrophoresis. Although the overall prevalence of this mutant allele was significantly higher in this population than in Japanese $(36 \% v 12 \%$, $\chi^{2}=63.2, P<0.001$ ), there was no statistically significant difference in the distribution of the alleles between the patients with Parkinson's disease and controls (Parkinson's disease: 42 wild type (wt), 41 heterozygotes (he), 13 mutant homozygotes (mu); $v$ controls: $23 \mathrm{wt}, 30 \mathrm{he}, 7 \mathrm{mu})\left(\chi^{2}\right.$ $(3 \times 2$ table $)=0.79 ; P=0.68)$. Therefore, it seems that the Hhal polymorphism is not, by itself, of major significance to the aetiology of Parkinson's disease in Caucasians. $[\mathrm{ABN}]$

CLINICAL, CSF, AND MRI FINDINGS IN DEVIC'S NEUROMYELITIS OPTICA

JI O'Riordan, H Gallagher, DPE Kingsley, EJ Thompson, WI McDonald, DH Miller. Institute of Neurology, London, UK

Eleven patients with Devic's neuromyelitis optica are described. The mean age of presentation was 36.3 years and 10 patients were female. Severe deficits in ambulation and vision were the rule rather than the exception with vision reduced to counting fingers or worse in nine patients and six remaining wheelchair bound. There was negative local synthesis of CSF oligoclonal bands in nine. Two patients had evidence of a connective tissue disorder and six had nonspecific increases of various autoantibodies. Ten patients underwent MRI of brain and spinal cord. In nine there were diffuse abnormalities involving both cervical and thoracic cords with extensive cord swelling. The remaining patient had linear signal change in the upper cervical and thoracic cords. A brain MRI was normal in six; in four there were multiple deep white matter lesions. Two patients had signal change in the optic nerves; one with associated swelling. Devic's neuromyelitis optica remains a disorder of unknown aetiology with poor outcome. Thus MRI is a valuable tool in diagnosis, aiding the prognostic evaluation by the physician.

[ABN]
FUNCTIONAL INTEGRTY OF CORTICAL DYSPLASIA

MP Richardson, MJ Koepp, DJ Brooks, DR

Fish, JS Duncan. Institute of Neurology and MRC Cyclotron Unit, London, UK

The extent of altered benzodiazepine receptor density in focal cortical dysgenesis was determined. It was hypothesised that the area of functional abnormality in cortical dysgenesis exceeds the structural abnormality seen on MRI.

${ }^{11} \mathrm{C}-F$ lumazenil PET was performed to determine volume of distribution (" ${ }^{11} \mathrm{C}-\mathrm{FMZ}$ Vd) in four patients. These scans were co-registered with high resolution MRI pixel by pixel. The extent of dysplasia was defined on the MRI and regions of interest placed on the abnormality, surrounding cortex, distant cortex, and in corresponding areas in the opposite hemisphere. The same set of regions of interest was applied to the PET and ${ }^{11} \mathrm{C}-\mathrm{FMZ}-\mathrm{Vd}$ determined. The results were compared with 10 normal controls and expressed as asymmetry indices. Additionally, each of these same four patients' ${ }^{11}$ C-FMZ-Vd scans were analysed by Statistical Parametric Mapping (SPM), via automated volumetric normalisation, analysis of covariance (ANCOVA), and pixel-by-pixel $t$ test in comparison with 24 normal controls.

The regions of interest based approach showed significant differences between asymmetry indices in patients and controls for the lesion region $(P<0.01)$ and for the surrounding cortex $(P<0.02)$ but not for distant cortex. These findings were confirmed at the $P<0.001$ level in SPM, which additionally showed the anatomical extent of changes in detail. It was concluded that the existence of more widespread functional compared with structural abnormality may in part explain the poor outcome of focal resections in patients with focal dysplasia. [ABN]

NON-FATAL INJURIES IN AN UNSELECTED POPULATION OF PATIENTS WITH EPILEPSY D Smith, GA Baker, A Jacoby, DW Chadwick. Walton Centre for Neurology and Neurosurgery, Liverpool, UK

The excess mortality associated with epilepsy, and the factors responsible for this are well documented. Epidemiological data indicate that fatal accidents are overrepresented as a cause of death in epilepsy. Non-fatal accidents are much more common but their incidence, and associated factors, are not known with any certainty.

A postal questionnaire has been sent to a heterogenous, community based population ( $n>1000$ ) of patients with epilepsy. In addition to clinical and demographic details and previously validated scales of psychosocial wellbeing, this contains a series of questions about injuries; burns, head and dental trauma, fractures, and submersion accidents incurred in the previous 12 months.

Data are available on 346 adults. Burns and scalds, head injury, dental injury, fracture, and submersion accidents are reported in $14 \%, 18 \%, 8 \%, 5 \%$, and $13 \%$ respectively.

Multivariate analysis, designed to identify factors associated with these injuries, are being conducted. These data should permit estimates of individual risk, which facilitates sensible patient counselling, including advice about preventative measures, without engendering undue alarm.

[ABN]

FELBAMATE INHIBITS VERATRIDINE INDUCED GLUTAMATE RELEASE FROM MOUSE CORTEX

J Srinivasan, A Richens, JA Davies. University of Wales College of Medicine, Cardiff, UK

Felbamate, a new anticonvulsant drug, has an affinity for the strychnine insensitive glycine site on the NMDA receptor. This study compared the effects of felbamate and 5,7 dichlorokynurenic acid (5,7 DCKA), a potent glycine site antagonist, on glutamate release.

Glutamate was released from coronal slices of mouse cortex by potassium ( 60 $\mathrm{mM})$ or veratridine $(20 \mu \mathrm{M})$. Perfusate was assayed for glutamate by high performance liquid chromatography. Basal release of glutamate was $3-5 \mathrm{pmol} / \mathrm{mg}$ tissue $/ 2 \mathrm{~min}$. The first pulse of potassium or veratridine induced a pronounced (eight to ninefold) release of glutamate over basal and the second pulse produced an average release of 90 $(8 \%)$ and $67(6 \%)$ respectively of the first pulse. Felbamate $(100 \mu \mathrm{M}$ to $800 \mu \mathrm{M})$ had no effect on basal or potassium stimulated release of glutamate. Veratridine stimulated release was significantly inhibited by felbamate in concentrations of $400 \mu \mathrm{M}(39.2$ $(6 \%), \mathrm{n}=12, \mathrm{P}<0.01)$ and $800 \mu \mathrm{M}(37.9$ (5\%), $\mathrm{n}=8, \mathrm{P}<0.01$ ). 5,7 DCKA (50 to $200 \mu \mathrm{M})$ had no effect on glutamate release.

The inhibitory effect of felbamate on glutamate release is probably unrelated to its affinity for the glycine site on the NMDA receptor and may be due to inactivation of sodium channels.

[ABN]

EUROPEAN COMMUNITY STROKE PROJECT: RESOURCE USE, COSTS, AND OUTCOME OF DIFFERENT CARE PACKAGES FOR STROKE J Stewart, R Howard, R Ross Russell, A Rudd, C Wolfe. St Thomas' Hospital, London, UK

Stroke imposes a major burden on health resources worldwide; in the United Kingdom acute stroke care alone costs $4 \cdot 6 \%$ of the NHS budget. There is a 10-fold variation in age standardised mortality for stroke in people under 65 years across Europe, which is not reflected in the incidence rates and therefore may be related to different patterns of care for stroke patients.

The EC stroke project has been established to explore the relation between resource use, costs, and outcome of stroke. The study involving 24 hospitals from nine European countries, commenced on 1 January 1993. Methodology has been developed to enable standardised data collection to describe stroke care in terms of type and severity of stroke, hospital admission rates, bed type, duration of stay, use of tests, amount of rehabilitation, and outcome at one year.

Initial resource data on 2438 stroke patients are reported for the first year. In two Spanish centres, $81 \%$ of patients were admitted to neurology beds compared with $0 \%$ in two British centres. In one German 
centre, $94 \%$ of patients received brain imaging, $80 \%$ carotid Dopplers, and $36 \%$ cerebral angiography, compared with $30 \%, 0 \%$, and $1 \%$ respectively in one British centre. It will be interesting to correlate this wide variation in resource use with outcome at one year. [ABN]

SPINAL MULTIPLE SCLEROSIS: A CLINICAL AND MRI STUDY

JW Thorpe, D Kidd, IF Moseley, DAS Compston, WI McDonald, DH Miller. Institute of Neurology, London and University of Cambridge, Cambridge, UK

Although MRI detects the white matter lesions of multiple sclerosis within the brain with high sensitivity, a minority of patients have normal brain imaging. Nineteen patients are described, selected from over 170 who had undergone brain and spinal cord imaging, in whom minimal $(n=9)$ or no $(n=10)$ brain abnormalities were found. Eleven had clinically definite or laboratory supported definite multiple sclerosis according to the Poser criteria; four had clinically probable disease, and four had progressive isolated myelopathy. All had presented with symptoms and signs referable to the spinal cord or optic nerves. Eleven had a primary progressive course, seven relapsing-remitting and only one secondary progressive. Moderate or severe disability was the rule in the primary progressive patients whereas the relapsing remitting patients were minimally disabled. All had at least one lesion visible in the spinal cord. In patients in whom the diagnosis of multiple sclerosis is not supported by abnormalities on brain MRI, imaging of the spinal cord can be of considerable value.

[ABN]

"PURE" AUTOSOMAL DOMINANT SPASTIC PARAPLEGIA WITH LATE ONSET DEMENTIA: A FAMILY STUDY

S Webb, J Hutchinson, M Hutchinson. St Vincent's Hospital, Dublin, Eire

The phenotype of "pure" forms of hereditary spastic paraplegia (HSP) is highly variable. Familial dementia has not been reported in either the pure or complicated forms of HSP. A family with autosomal dominant HSP is presented. Thirty eight of the 54 living members of the family were examined; there were 11 affected persons of the 26 members over the age of 30 . Both the severity of the paraplegia and the age of onset (20-50 years) varied considerably, with one asymptomatic person at the age of 62 years.

One member died of a four year dementing illness at the age of 62 . Four other members of this sibship aged $62-70$ had neuropsychological examination; all showed evidence of a dementia. Vocabulary, reading, and computational abilities were relatively preserved by contrast with a pronounced deficit in perceptual and constructional ability. Verbal learning and memory were below expectation but not as dramatically impoverished as visual recall. All four profiles were remarkably similar, worsened with age, and all four tended to use overt compensatory verbal analysis in visuoconstructive tasks. Magnetic resonance imaging showed a generalised atrophy. This dementia is difficult to classify; it differs from Alzheimer's disease in having intact reasoning and relatively preserved verbal skills and is characterised by a progressive predominantly parietal cognitive loss in the seventh decade. [ABN] 